\title{
Study on Mutation Resistance to Imatinib in Chronic Myeloid Leukemia Patients from West India
}

\author{
Ankit Darji 1, *, Praful Bharadia ${ }^{2}$ \\ ${ }^{1}$ Department of Pharmacy, Hemchandracharya North Gujarat University, Patan, Gujarat, India \\ ${ }^{2}$ L. M. College of Pharmacy, Navrangpura, Ahmedabad, Gujarat, India
}

Email address:

ankitdarji1627@gmail.com (A. Darji), pdbharadia@yahoo.com (P. Bharadia)

${ }^{*}$ Corresponding author

\section{To cite this article:}

Ankit Darji, Praful Bharadia. Study on Mutation Resistance to Imatinib in Chronic Myeloid Leukemia Patients from West India. Science Journal of Analytical Chemistry. Vol. 1, No. 1, 2021, pp. 1-17. doi: 10.11648/j.sjac.20210901.11

Received: March 6, 2020; Accepted: April 1, 2020; Published: January 4, 2021

\begin{abstract}
Imatinib is a type of protein tyrosine kinase inhibitor which inhibits the constitutive abnormal tyrosine kinase created by the Philadelphia chromosome i.e. the BCR-ABL tyrosine kinase, abnormality in CML patient. The aim of the study is to assess the response of imatinib in CML patients and to observe resistance to imatinib. Study was performed at Ahmedabad, Gujarat, India. Dose of 400, 600, $800 \mathrm{mg}$ of Imatinib was found to be prescribed to all patients during the study. Comparison of laboratory parameters and PCR data were done after measurement by RT-PCR method. Total 256 patients with CML were enrolled in the study. 196 patients had completed study as per protocol. 38 patients were newly diagnosed whereas 158 patients were already diagnosed with CML. $89.29 \%(n=175)$ of patients achieved complete haematological response, Complete MolR were achieved in $\mathrm{n}=41$ at $6^{\text {th }}$ months, $\mathrm{n}=1$ at $12^{\text {th }}$ month $\& 18^{\text {th }}$ month and no patient was found with none CyR out of 196 patients; no patient were found with minimal CyR at $6^{\text {th }}$ month, 2 patient were at $12^{\text {th }}$ month and 3 patients were at $18^{\text {th }}$ month. Mean PCR value (BCR-ABL/ABL ratio) in patient was found $0.245 \pm 1.16$ at Day $0,0.824 \pm 1.51$ at $6^{\text {th }}$ month, $4.086 \pm 9.58$ at $12^{\text {th }}$ month and $6.713 \pm 11.32$ at $18^{\text {th }}$ month visit. In conclusion, it was observed that resistance to imatinib might be developed within an average time of 12 months in the patients due to which survival rate was drastically reduced.
\end{abstract}

Keywords: Cancer, CML, Imatinib, BCR-ABL, Mutation, Resistance

\section{Introduction}

Cancer is defined as uncontrolled cell growth. It is a class of diseases in which cell, or a group of cells display uncontrolled growth (division beyond the normal limits), invasion (intrusion on and destruction of adjacent tissues), and sometimes metastasis (spread to other locations in the body via lymph or blood). [1,2]

There are four predominant types of Cancer:

1. Carcinoma,

2. Sarcoma,

3. Leukemia, and

4. Lymphoma

Leukemia are cancers of the bone marrow, which leads to the over production and early release of immature leukocytes (white blood cells). Leukemia [2, 4] (leukos "white"; aima "blood") is a type of cancer of the blood or bone marrow that is characterized by an abnormal increase of white blood cells. [3]

Chronic myelogenous (or myeloid) leukemia (CML), also known as chronic granulocytic leukemia (CGL), is a cancer of the white blood cells.4 CML is a clonal bone marrow stem cell disorder in which proliferation of mature granulocytes (neutrophils, eosinophils, and basophils) and their precursors is the main finding. It is a type of myeloproliferative disease associated with a characteristic chromosomal translocation called the Philadelphia chromosome.

Ninety- five percent of patients display a characteristic $t$ (9s22) chromosome translocation, the Philadelphia chromosome.5,6 In 1973, Dr. Janet Rowley determined that the shortened chromosome 22, the so-called Philadelphia (Ph) chromosome, was the product of a reciprocal translocation between the long arms of chromosomes 9 and 22, $\mathrm{t}(9: 22)$ (q34; q11).

According to the characteristics and progression of the disease, chronic myeloid leukemia falls into 3 main 
phases/stages. [2, 6, 7]

1. Chronic Phase

2. Accelerated Phase

3. Blast Crisis

1. Chronic Phase

The first stage, lasting from 3 to 5 years, is an early chronic phase in which the patient is minimally symptomatic. At this point, there is usually less than $5 \%$ immature or blast cells present in the bone marrow. In this early phase of the disease, the leukemic cells retain the ability to differentiate and mature into granulocytes.

\section{Accelerated Phase}

The leukemia may then go through a transition phase or accelerated phase $(5 \%-30 \%$ blast cells) of several months duration, in which the symptoms are more pronounced and more refractory to medication.

The WHO criteria are perhaps most widely used, and define the accelerated phase by any of the following:

1) $10-19 \%$ myeloblasts in the blood or bone marrow

2) $>20 \%$ basophils in the blood or bone marrow

3) Platelet count $<100,000$, unrelated to therapy

4) Platelet count $>1,000,000$, unresponsive to therapy

5) Cytogenetic evolution with new abnormalities in addition to the Philadelphia chromosome

6) Increasing splenomegaly or white blood cell count, unresponsive to therapy

The patient is considered to be in the accelerated phase if any of the above is present. The accelerated phase is significant because it signals that the disease is progressing and transformation to blast crisis is imminent.

\section{Blast Crisis}

Finally, CML invariably progresses to a blast phase $(>30 \%$ blast cells), which causes a fatal leukemic blast crisis, unless the leukemic clone has been eradicated and normal hematopoiesis is restored. Blast crisis is characterized by fevers and bleeding complications, similar to the presentation of acute leukemia, and unless the patient receives treatment, the risk of mortality is extremely high. At this time, the only potential cure for CML is an AHCT (Allogenic stem cell transplantation). Some patients may already be in the accelerated phase or blast crisis by the time they are diagnosed.

Imatinib is a tyrosine kinase inhibitor that shows promise in CML. The BCR-ABL transcript of CML has tyrosine kinase activity, which is necessary for its ability to cause leukemic transformation. Imatinib is an ABL protein tyrosine kinase inhibitor. Imatinib is available as $100-\mathrm{mg}$ PO capsules or 400-mg PO tablets. [5]

Imatinib mesylate is a protein-tyrosine kinase inhibitor that inhibits the bcr-abl tyrosine kinase, the constitutive abnormal tyrosine kinase created by the Philadelphia chromosome abnormality in chronic myeloid leukemia (CML). It inhibits proliferation and induces apoptosis in bcr-abl positive cell lines as well as fresh leukemic cells from Philadelphia chromosome positive chronic myeloid leukemia. In vivo, it inhibits tumor growth of bcr-abl transfected murine myeloid cells as well as bcr-abl positive leukemia lines derived from CML patients in blast crisis. $[8,9]$
Imatinib is also an inhibitor of the receptor tyrosine kinases for platelet-derived growth factor (PDGF) and stem cell factor (SCF), c-kit, and inhibits PDGF- and SCF mediated cellular events. $[8,9]$

The recommended dose of imatinib mesylate is 400 $\mathrm{mg}$ /day for adult patients in CML chronic phase and 600 $\mathrm{mg}$ /day for CML accelerated phase/blast crisis. The given prescribed dose should be given orally with meal and full glass of water. $[9,10]$

Despite imatinib can induce significant $\mathrm{HR}, \mathrm{CgR}$ and even MolR in CML-CP patients, some patients fail to response optimally to imatinib or progress to advanced disease. In the five-year follow-up of IRIS trial, $6 \%$ progressed to advanced disease, $3 \%$ had a hematologic relapse and 5\% had a loss of $\mathrm{MCgR}$. Moreover, response rate is lower and transient for most patients with advanced phases of CML. [11-17]

Therefore, studies into the mechanism of imatinib-resistance and the derivation of management strategies are essential to the optimized care of CML. [11-17]

In most patients with acquired imatinib resistance, the BCR-ABL kinase was still activated despite continuation of imatinib treatment. Point mutation of the kinase domain (KD) of BCR-ABL protein was found to be the commonest cause for the failure of inhibition and many different mutations were identified. On the other hand, KD mutation as the cause for primary resistance is much less common. [11-17]

Point mutations were found mainly clustered into several regions of the $\mathrm{KD}$ : the contact site of imatinib, the P-loop (a.a. 248-256) and the activation loop (a.a.381-402). Point mutation leads to a single amino acid change in the KD and a change in KD conformation. This either impairs binding of imatinib to the contact site or prevent BCR-ABL protein from achieving an inactive conformation to which imatinib exclusively binds. [11-17]

The clinical significance of different point mutations and their drug resistance varies. Studies showed that mutant clone of BCR-ABL positive cells can pre-exist before imatinib treatment and the selective pressure exerted by imatinib may confer growth advantage of the mutant and final emergence of clinical resistance. While several BCR-ABL mutants are still sensitive to higher concentration of imatinib, the mutant T315I (change of threonine to isoleucine at residue 315) is completely resistant due to the interruption of critical contact point to imatinib. [11-17]

Apart from KD mutation, kinase activity of BCR-ABL protein can also be reactivated through over expression of BCR-ABL protein. This can either be due to BCR-ABL gene amplification or an increase in BCR-ABL transcript level. Resistance to imatinib may also due to a reduced intracellular drug concentration. Intracellular concentration of imatinib is determined by the balance of active influx and efflux of drug into or out of the cell. Imatinib is a substrate of P-glycoprotein which is a protein for drug efflux. Over expression of P-glycoprotein had been found associated with imatinib resistance by increased drug efflux. The level of drug influx transporter protein, human organic cation transporter 1 (hOCT1), varies greatly in different patients and 
may contribute to variable imatinib sensitivity. In addition, plasma imatinib levels were shown to have wide variation among patients and this may be an important factor contributing to primary imatinib resistance. $[18,19,20]$

Besides BCR-ABL dependent mechanism of resistance, studies also demonstrate a role for BCR-ABL independent mechanisms in imatinib resistance. The relationship between secondary chromosomal aberrations, clonal evolution and imatinib resistance is poorly understood. Over expression and activation of Src family kinase Lyn in the mediation of drug resistance is recently reported. [18, 19, 20]

The objective of current study was to quantify the mutation resistance to specific drug therapy in CML patients.

\section{Materials and Methods}

Study design was drafted, presented at HNGU and it was approved from institution as well as from institutional ethics committee, Sangini Hospital, 2nd floor, Sangini Complex, Near Doctor House, Parimal Crossing, Ahmedabad, Gujarat, India - registered with CDSCO.

Consent was obtained from patient in vernacular language prior to enrollment in study. Total 256 patients were enrolled from 14 Nov 2014 to 19 Jun 2017. Out of 256 patients, 196 patients had completed study as per protocol.

\section{ELIGIBILITY CRITERIA:}

Inclusion Criteria:

1) Age above 18 years male or female

2) Diagnosis of CML in chronic phase with cytogenetic confirmation of Philadelphia chromosome of $(9 ; 22)$ translocations or presence of BCR-ABL.

3) Patients having chronic phase CML, who are on imatinib therapy more than 12 months.

4) Informed consent were taken from each patient.

5) ECOG Performance status $\leq 2$

Exclusion Criteria:

1) Women who are breast feeding or pregnant

2) Patients with any significant history of non-compliance to medical regimens

3) Altered hepatic or renal function as defined by AST/ALT or bilirubine $>3$ times upper normal limits (UNL) and by creatinine $>20 \mathrm{mg} / \mathrm{L}$

4) On concurrent medication for CML or any other tyrosine kinase inhibitor

5) Patient having cardiac disease

6) Presence of severe and/or uncontrolled concurrent medical disease (e.g., uncontrolled diabetes, uncontrolled chronic renal disease, uncontrolled liver disease, including chronic viral hepatitis judged at risk of reactivation, uncontrolled active infection, such as HIV infection, etc.)

As per protocol, total approximately 200 patients were required for analysis. Therefore, total 256 patients, diagnosed with CML were enrolled. Out of 256 patients, 196 patients completed the study as per protocol requirements and all visits as per following:

1. Visit 1: Day 0 - Screening,
2. Visit 2: Month 6,

3. Visit 3: Month 12,

4. Visit 4: Month 18 - End of Study.

TREATMENT DURING STUDY

Dose of $400 \mathrm{mg}$ or $600 \mathrm{mg}$ of Imatinib were found to be prescribed to all patients during the study and patients who were on Imatinib were only enrolled in the study. Some of the patient were also prescribed $800 \mathrm{mg}$ of Imatinib (400 mg twice daily) if required.

PRESTUDY ANALYSIS

Following information and data related to each patient were collected before including the patient into the study. Patient which were found suitable on the basis of Eligibility criteria in the study.

DEMOGRAPHY

Age, sex, height, weight, BMI

MEDICAL HISTORY / CLINICAL EXAMINATION

1) Any drug / tobacco addiction, food habits, alcohol

2) Physical examination

3) Family history, past history

VITAL SIGNS

At the time of pre study examination, temperature, pulse rate and blood pressure were recorded for all patients.

\section{CLINICAL LABORATORY TESTS}

Laboratory tests were done prior to the study during screening for all patients. These tests involve hematology, biochemistry as indicated as part of routine clinical practice.

DRUG ADMINISTRATION

It was ensured that patients were treated with imatinib oral dose. The prescribed dose should be administered orally, with a meal and full glass of water.31,34

BLOOD SAMPLE COLLECTION

$5 \mathrm{ml}$ blood sample was taken from the CML patients prior to the administration of the next dose.

TOTAL BLOOD LOSS

Total blood loss was be $5 \mathrm{ml} /$ visit for the each patient during study.

\section{POST STUDY PROCEDURE}

LABORATORY INVESTIGATION

Blood samples were collected from the patient to see the haematological response, cytogenetic response and molecular response, which was correlated to measure resistance of patient with imatinib.13,39

\section{Results}

Table 1. Patient Characteristics.

\begin{tabular}{ll}
\hline Characteristics & Number of patients \\
\hline Total No. of patients enrolled & 256 \\
Total No. of patients completed & 196 \\
Gender & \\
Male & 141 \\
Female & 55 \\
Age (Mean) & $47.07 \pm 11.64$ \\
Age (Range) & $17-69$ years \\
\hline
\end{tabular}

Patients with chronic myeloid leukemia were treated with standard imatinib regimens of 400 or $600 \mathrm{mg}$, determined by 
clinical judgment on presentation. In the present study, patients newly diagnosed with CML requiring oral dose of 400 or $600 \mathrm{mg}$ per day, and patients already diagnosed with CML who were on imatinib therapy for not more than one year were considered.

Patients were divided into different groups according to their hematological response, molecular response and cytogenetic response.

Hematologic Response

In first group patients are divided into complete haematological response and No haematological response. $89.29 \%(\mathrm{n}=175)$ of patients achieved complete haematological response and $10.71 \%(n=21)$ did not achieve haematological response.

Molecular Response

(a) Complete molecular response

In second group, we divided our patients into those with CMolR ( $\mathrm{n}=41$ at 6 th months, 01 at 12 th month \& 18th month) and those without CMolR ( $\mathrm{n}=124$ at 6 th months, 182 at 12 th month \& 194 at 18th month), such that level of BCR-ABL transcripts as the test variable would yield a threshold value for imatinib levels that correlates with a molecular response.

(b) Major molecular response

In third group we divided our patients into those with MMolR ( $\mathrm{n}=72$ at 6 th months, 14 at 12 th month \& 02 at 18 th month) and those without MMolR ( $\mathrm{n}=124$ at 6 th months, 182 at 12 th month $\& 194$ at 18 th month), such that level of BCR-ABL transcripts as the test variable would yield a threshold value for imatinib levels that correlates with a molecular response.

Cytogenetic response

In the fourth group, we divided our patients into those with none CyR, minimal CyR, minor $\mathrm{CyR}$, partial $\mathrm{CyR}$ and complete CyR.

1) No patient was found with none CyR out of 196 patients.

2) No patient were found with minimal CyR at 6th month, 2 patient were at 12 th month and 3 patients were at 18 th month.

3) No patient were found with minor CyR at 6th month, 2 patient were at 12 th month and 3 patients were at 18 th month.

4) 53 patients were found with partial $\mathrm{CyR}$ at 6th month, 119 patients were at 12 th month and 150 patients were at 18 th month.

5) Whereas 42 patients were found with complete CyR at 6th month, 2 patients were at 12 th month and 1 patient were at 18 th month.

All 196 patients visited site at every 6 months as required for CML patient and recommended by respective treating doctor.

Laboratory value re-presented in this section are in the form of Mean $\pm \mathrm{SD}$ :

Mean $\mathrm{Hb}$ value was found $11.5 \pm 1.92 \mathrm{~g} / \mathrm{dL}$ at Day 0 , $12.0 \pm 1.73 \mathrm{~g} / \mathrm{dL}$ at 6 th month, $12.5 \pm 1.60 \mathrm{~g} / \mathrm{dL}$ at 12 th month and $12.7 \pm 1.39 \mathrm{~g} / \mathrm{dL}$ at 18 th month visit by patients.
Mean RBC value was found $4.1 \pm 0.79 / \mathrm{cmm}$ at Day 0 , $4.4 \pm 0.71 / \mathrm{cmm}$ at 6 th month, $4.7 \pm 0.69 / \mathrm{cmm}$ at 12 th month and $4.8 \pm 0.61 / \mathrm{cmm}$ at 18 th month visit by patients.

Mean WBC value was found $45170.4 \pm 96300.94 / \mathrm{cmm}$ at Day 0, $17236.1 \pm 28477.32 / \mathrm{cmm}$ at 6th month, $12637.8 \pm 21387.45 / \mathrm{cmm}$ at 12th month and $9997.2 \pm 10830.94 / \mathrm{cmm}$ at 18 th month visit by patients.

Mean Platelets count was found 274770.4 \pm 241751.63 /cmm at Day 0, 288515.3 $\pm 197887.52 / \mathrm{cmm}$ at 6 th month, $319924.5 \pm 186724.88 / \mathrm{cmm}$ at 12th month and $321591.8 \pm 102412.02 / \mathrm{cmm}$ at 18 th month visit by patients.

Mean blast cells count was found $8.3 \pm 13.67 \%$ at Day 0 , $3.3 \pm 3.87 \%$ at 6 th month, $2.3 \pm 4.09 \%$ at 12 th month and $2.7 \pm 3.61 \%$ at 18 th month visit by patients.

Mean promyelocytes value was found $4.7 \pm 2.09 \%$ at Day 0 , $2.8 \pm 2.62 \%$ at 6 th month, $2.4 \pm 2.95 \%$ at 12 th month and $2.3 \pm 1.89 \%$ at 18 th month visit by patients.

Mean myelocytes value was found $6.4 \pm 4.53 \%$ at Day 0 , $3.1 \pm 2.53 \%$ at 6 th month, $3.0 \pm 2.83 \%$ at 12 th month and $3.3 \pm 2.63 \%$ at 18 th month visit by patients.

Mean metamyelocytes value was found $6.7 \pm 3.85 \%$ at Day $0,3.6 \pm 3.16 \%$ at 6 th month, $3.3 \pm 3.73 \%$ at 12 th month and $2.6 \pm 2.61 \%$ at 18 th month visit by patients.

Mean band form cells count was found $4.6 \pm 2.03 \%$ at Day $0,2.5 \pm 1.02 \%$ at 6 th month and $2.2 \pm 1.83 \%$ at 12 th month visit by patients.

Mean neutrophils count was found $54.8 \pm 13.63 \%$ at Day 0 , $53.0 \pm 11.51 \%$ at 6 th month and $45.8 \pm 12.59 \%$ at 12 th month visit by patients.

Mean lymphocytes count was found $29.4 \pm 15.08 \%$ at Day $0,28.3 \pm 12.81 \%$ at 6 th month and $26.1 \pm 14.59 \%$ at 12 th month visit by patients.

Mean monocytes count was found $5.4 \pm 2.74 \%$ at Day 0 , $4.7 \pm 2.77 \%$ at 6 th month and $3.3 \pm 2.79 \%$ at 12 th month visit by patients.

Mean eosinophil count was found $3.8 \pm 2.89 \%$ at Day 0 , $3.1 \pm 2.69 \%$ at 6 th month and $2.2 \pm 2.14 \%$ at 12 th month visit by patients.

Mean basophils count was found $2.5 \pm 3.53 \%$ at Day 0 , $2.5 \pm 11.64 \%$ at 6 th month and $1.7 \pm 2.65 \%$ at 12 th month visit by patients.

Mean normoblast count was found $1.3 \pm 0.58 / 100 \mathrm{WBC}$ at Day $0,1.8 \pm 0.50 / 100 \mathrm{WBC}$ at 6 th month, $1.0 \pm 0 / 100 \mathrm{WBC}$ at 12th month and $2.0 \pm 0 / 100 \mathrm{WBC}$ at 18 th month visit by patients.

Mean SGPT value was found $23.09 \pm 11.33 \mathrm{U} / \mathrm{L}$ at Day 0 , $27.67 \pm 14.61 \mathrm{U} / \mathrm{L}$ at 6 th month, $28.08 \pm 11.96 \mathrm{U} / \mathrm{L}$ at 12 th month and $29.23 \pm 6.93 \mathrm{U} / \mathrm{L}$ at 18 th month visit by patients.

Mean creatinine value was found $0.74 \pm 0.16 \mathrm{mg} / \mathrm{dL}$ at Day $0,0.80 \pm 0.35 \mathrm{mg} / \mathrm{dL}$ at 6 th month, $0.81 \pm 0.29 \mathrm{mg} / \mathrm{dL}$ at 12 th month and $0.87 \pm 0.22 \mathrm{mg} / \mathrm{dL}$ at 18 th month visit by patients.

Mean PCR value (BCR-ABL/ABL ratio) was found $0.245 \pm 1.16$ at Day $0,0.824 \pm 1.51$ at 6 th month, $4.086 \pm 9.58$ at 12 th month and $6.713 \pm 11.32$ at 18 th month visit by patients. 


\section{Discussion}

\section{HEMATOLOGIC RESPONSE}

Patients were divided into two groups:

1. Complete haematological response and

2. No haematological response.

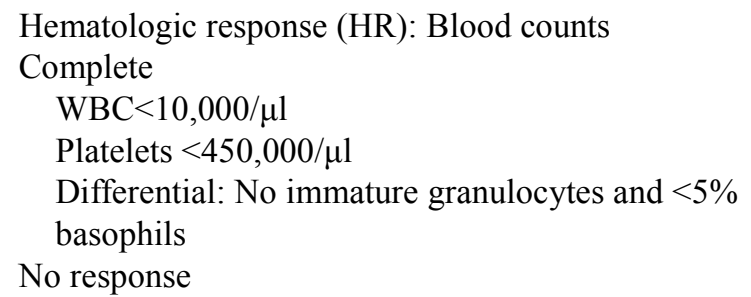

In current study, after 6 month of treatment period, $18.57 \%$ $(n=154)$ of CML patient found with complete haemtological response (CHR), whereas after 12 months of treatment, 80.61\% of CML patient gave CHR, and $89.29 \%(n=175)$ of CML patients achieved complete haematological response after 18 months of treatment period. $10.71 \%(n=21)$ CML patients did not achieve haematological response after 18 months of treatment period.

As per F. Razmkhah et al., in total of 27 patients (90\%) showed complete hematologic response, while 14 patients (46.7\%) showed CMR, 13 patients (43.3\%) showed PMR, and 3 patients (10\%) showed NMR. All patients with CMR showed hematologic response, whereas 2 patients with PMR and 1 patient with NMR showed no hematologic response. 21

Similarly as per H. Kantarjian et al., a complete hematologic responses were reported for 430 of the 454 patients studied ( 95 percent). The median time to a complete hematologic response was 0.7 month; 86 percent of patients who had a response within 3 months. 22

As per Delamain MT et al., a study was performed to monitor BCR-ABL levels in CML patients treated with imatinib in chronic phase for the treatment. Among all patient 95\% patients achieved complete hematologic response (CHR). 23

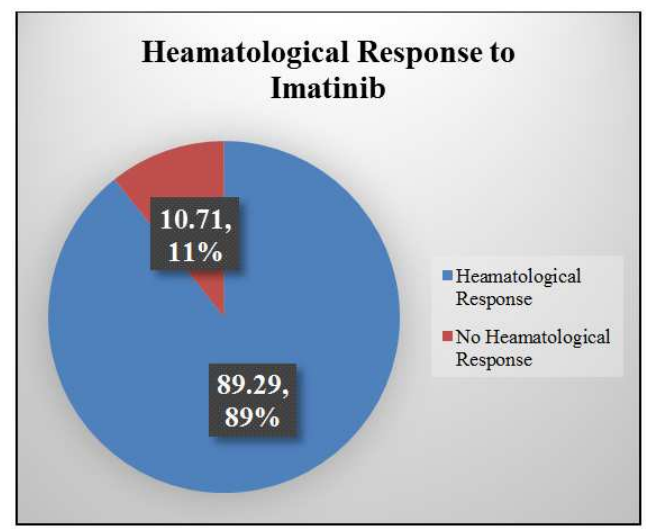

Figure 1. Heamatological Response to Imatinib.

As per sawyer et al., a phase II study conducted to determine whether imatinib, a potent inhibitor of the oncogenic Bcr-Abl tyrosine kinase, could induce sustained hematologic responses lasting at least 4 weeks in at least $15 \%$ of patients with CML in previously untreated myeloid blast crisis, when administered at well-tolerated doses defined in an earlier phase I study. They found that orally administered imatinib induced a sustained hematologic response in $36 \%$ of previously untreated patients, including a $\mathrm{CHR}$ in $9 \%$ of patients. 24

According to data presented above, it seems that patient giving a good haematological response to Imatinib treatment.

MOLECULAR RESPONSE

Molecular response are mainly divided in complete molecular response (Partial, Minor \& Minimal), Major molecular response and No molecular response.

Cytogenetic response (CyR): Ph-positive metaphase

Complete: $0 \%$

Partial: $1 \%-35 \%$

Minor: $36 \%-65 \%$

Minimal: $66 \%-95 \%$

(a) Complete molecular response

In this group, we categorised patients into those with CMolR ( $n=41$ at 6 th months, 01 at 12 th month \& 18 th month) and those without CMolR ( $\mathrm{n}=124$ at 6 th months, 182 at 12 th month \& 194 at 18th month), such that level of BCR-ABL transcripts as the test variable would yield a threshold value for imatinib levels that correlates with a molecular response.

(b) Major molecular response

In this group, we categorised patients into those with MMolR ( $\mathrm{n}=72$ at 6 th months, 14 at 12 th month $\& 02$ at 18 th month) and those without MMolR ( $=124$ at 6 th months, 182 at 12th month \& 194 at 18th month), such that level of BCR-ABL transcripts as the test variable would yield a threshold value for imatinib levels that correlates with a molecular response.

(b) No molecular response

Out of 196 patients, only $6(3 \%)$ patients did not have any molecular response till 18 months of treatment duration.

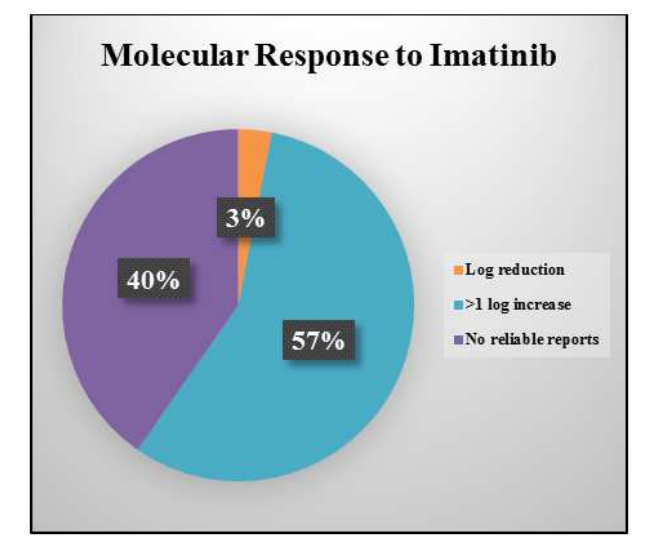

Figure 2. Molecular Response to Imatinib (After 18 months).

Molecular monitoring accomplishes by detecting the presence of BCR-ABL1 mRNA using real-time quantitative polymerase chain reaction (RQ-PCR). Molecular monitoring is capable of detecting low levels of disease and is $>3$ logs more sensitive than conventional cytogenetics. In addition, the analysis can be performed on peripheral blood samples which makes the process more convenient than bone marrow sampling. Molecular responses are quantified by measuring 
the reduction in BCR-ABL1 transcripts relative to a standardized baseline. 25

In the Insulin Resistance Intervention after Stroke (IRIS) trial, patients in the imatinib group, who had a reduction in the level of BCR-ABL1 transcripts of $>3 \operatorname{logs}$ compared to the standardized baseline had a negligible risk of disease progression over the subsequent 12 months. As a result, a major molecular response (MMR) was defined as a 3-log reduction or a BCR-ABL1 (IS) $=0.1 \% .25$

As per F. Razmkhah et al., out of 30 enrolled patients, 14 patients $(46.7 \%)$ showed CMR, 13 patients (43.3\%) showed PMR, and 3 patients (10\%) showed NMR.38 Moreover to above information by F. Razmkhah et al., 3 patients showed NMR out of which 2 showed complete haematological response. Therefore, it has been concluded that patient and therapy monitoring based on hematologic response alone can be misleading and will compromise physicians' judgment. According to B. J. Druker et al., Complete hematologic responses were observed in 53 of 54 patients treated with daily doses of $300 \mathrm{mg}$ or more and typically occurred in the first four weeks of therapy. Of the 54 patients treated with doses of $300 \mathrm{mg}$ or more, cytogenetic responses occurred in 29 patients, including 17 patients (31 percent of the 54 patients who received this dose) with major responses ( 0 to 35 percent of cells in metaphase positive for the Philadelphia chromosome); 7 of these patients had complete cytogenetic remissions. 26

Similarly in current study, considering different parameters for considering haematological and molecular response, minimal 175 patients showed compete haematological response whereas 111 patients showed CMR after 18 months of treatment follow up.

\section{CYTOGENETIC RESPONSE}

Cytogenetic response was divided into none CyR, minimal CyR, minor CyR, partial CyR and complete CyR.

For cytogenetic response, following results were found in current study:

1) No patient was found with none CyR out of 196 patients.

2) No patient were found with minimal CyR at 6 th month, 2 patient were at 12 th month and 3 patients were at 18 th month.

3) No patient were found with minor CyR at 6th month, 2 patient were at 12 th month and 3 patients were at 18 th month.

4) 53 patients were found with partial $\mathrm{CyR}$ at 6th month, 119 patients were at 12 th month and 150 patients were at 18 th month.

5) Whereas 42 patients were found with complete CyR at 6th month, 2 patients were at 12 th month and 1 patient were at 18 th month.

Table 2. Cytogenetic response.

\begin{tabular}{llll}
\hline $\begin{array}{l}\text { Cytogenetic } \\
\text { Response (CyR) }\end{array}$ & $\begin{array}{l}\text { No. of Patients } \\
\text { at } 6 \text { month }\end{array}$ & $\begin{array}{l}\text { No. of Patients } \\
\text { at 12 month }\end{array}$ & $\begin{array}{l}\text { No. of Patients } \\
\text { at 18 month }\end{array}$ \\
\hline None CyR & 0 & 0 & 0 \\
Minimal CyR & 0 & 2 & 3 \\
Minor CyR & 0 & 2 & 3 \\
Partial CyR & 53 & 119 & 150 \\
Complete CyR & 42 & 2 & 1 \\
\hline
\end{tabular}

\section{Cytogenetic Response to Imatinib}

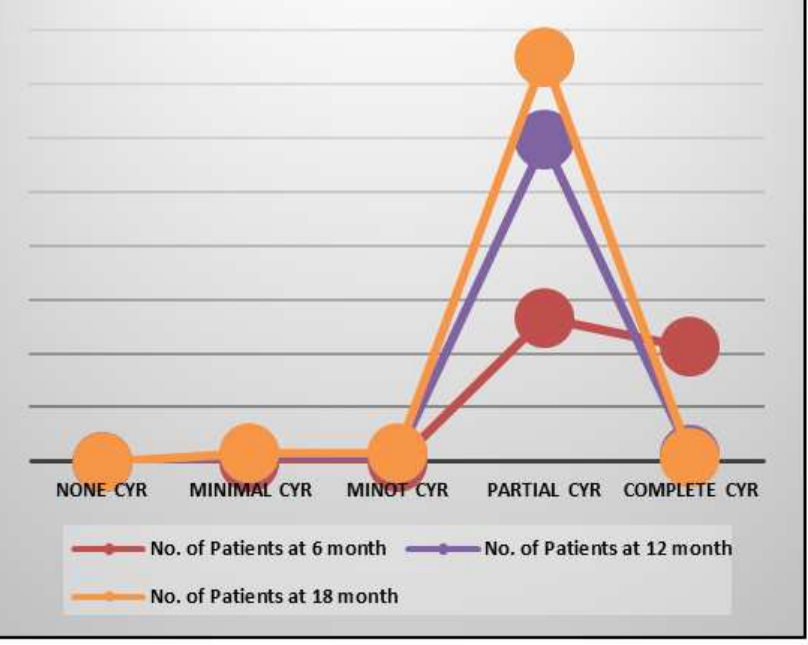

Figure 3. Cytogenetic Response to Imatinib (After 6, 12 \& 18 months).

As per T. D. Aissata et al. among in black African people, major cytogenetic response in $52 \%$, complete cytogenetic response in $26 \%$, partial cytogenetic response in $26 \%$, minor cytogenetic response in $30 \%$, minimal cytogenetic response in $15 \%$ people. [24]

From the above studies results and as per the current study, it has been observed that most of the patient obligating cytogenetic response to imatinib therapy however in all studies the percentage of response found different. There was not any pattern observed for cytogenetic response to imatinib therapy.

\section{LABORATORY VALUES \\ HAEMOGLOBIN $(\mathrm{Hb})$}

In current study the baseline mean $\mathrm{Hb}$ value was found $11.5 \pm 1.92 \mathrm{~g} / \mathrm{dL}$ (at Day 0), however due to erythropoietin concomitant treatment, mean $\mathrm{Hb}$ found as $12.0 \pm 1.73 \mathrm{~g} / \mathrm{dL}$ at $6^{\text {th }}$ month, $12.5 \pm 1.60 \mathrm{~g} / \mathrm{dL}$ at $12^{\text {th }}$ month and $12.7 \pm 1.39 \mathrm{~g} / \mathrm{dL}$ at $18^{\text {th }}$ month. Therefore, as per most of the supporting documents, it has been observed that $\mathrm{Hb}$ level increases with Imatinib and erythropoietin.



Figure 4. Hb Value Changes in Response to Imatinib (After 6, 12 \& 18 months).

During Hematological changes study in CML patients by K. 
Moshfeghi et al. both controlled (Indian Imatinib treatment arm) and reference (Iranian Imatinib treatment arm) groups showed a significant increasing trend of $\mathrm{Hb}$. [28]

Currently, it was also observed by K. M. Hasan et al. that there was a statistically significant difference in hemoglobin level, promyelocyte, and myelocyte count between those who achieved MMR/CMR versus those who did not, while other variables such as age, gender, initial total WBC count, spleen size, and LDH were not significantly correlated. [30]

A complete different observation was found in study by B. S. Poudyal et al. that withdrawal of the TKI and introduction of steroids led to recovery of $\mathrm{Hb}$. Whereas due to TKIs (Imatinib/Nilotinib), Hb level was reduced and not maintained even after blood transfusion. However, after introducing steroid, $\mathrm{Hb}$ level was maintained.

There was no major difference observed with age groups i.e. $\leq 35$ years, 36 to 50 years and $>50$ years of age.

There was no major difference observed with gender groups i.e. Male and Female.

There was no major difference observed with old or newly diagnosed patients.

\section{RED BLOOD CELLS}

In the current study the baseline mean $\mathrm{RBC}$ value was found $4.1 \pm 0.79 / \mathrm{cmm}$ (at Day 0), however mean $\mathrm{RBC}$ value was found $4.4 \pm 0.71 / \mathrm{cmm}$ at $6^{\text {th }}$ month, $4.7 \pm 0.69 / \mathrm{cmm}$ at $12^{\text {th }}$ month and $4.8 \pm 0.61 / \mathrm{cmm}$ at $18^{\text {th }}$ month visit.

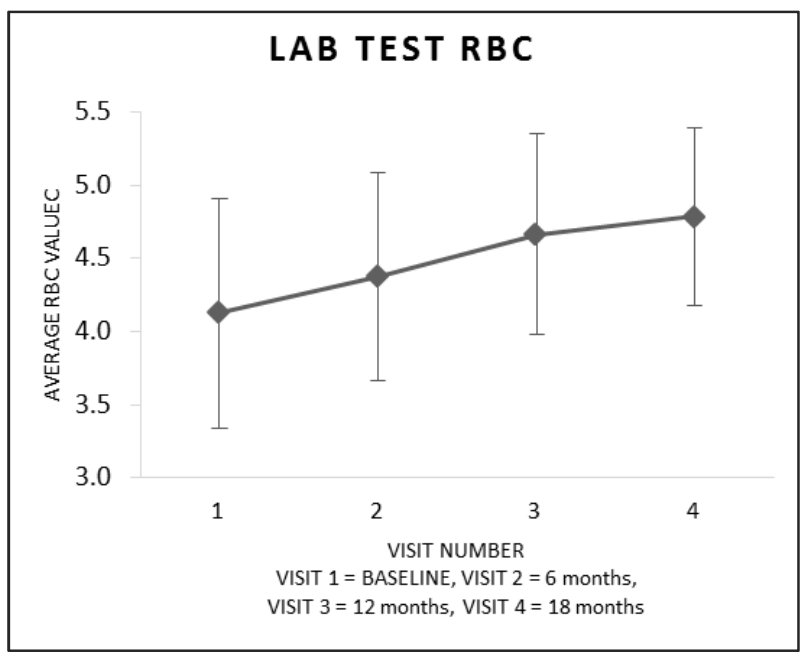

Figure 5. RBC Value Changes in Response to Imatinib (After 6, 12 \& 18 months).

No any specific study available which covers change in $\mathrm{RBC}$ count however as per current study increase the level of RBC count was observed.

As per D. Prihatni et al., out of 57 CML patients, there is no significant difference in $\mathrm{Hb}$ level, number of $\mathrm{RBC}$ and platelet cells. [31]

There was no major difference observed with age groups i.e. $\leq 35$ years, 36 to 50 years and $>50$ years of age.

There was no major difference observed with gender groups i.e. Male and Female.

There was no major difference observed with old or newly diagnosed patients.

\section{WHITE BLOOD CELLS}

In this study, we found that the optimal molecular response in the $1^{\text {st }}$ year was related to low $\mathrm{WBC}$ counts at presentation, and a BCR-ABL ${ }^{\mathrm{IS}}$ at 3 months $>10 \%$ and $\mathrm{WBC}$ count $>$ $150 \times 10 \mathrm{E} 9 / \mathrm{L}$ at presentation were independently poor prognostic factors for Molecular Response. Furthermore, patients with concurrent $\mathrm{WBC}>150$ and $\mathrm{BCR}-\mathrm{ABL}^{\mathrm{IS}} \leq 10 \%$ had a similarly low incidence of Molecular Response as patients with $\mathrm{BCR}-\mathrm{ABL}^{\mathrm{IS}}>10 \%$, whereas patients with concurrent $\mathrm{WBC} \leq 150$ and $\mathrm{BCR}-\mathrm{ABL}^{\mathrm{IS}} \leq 10 \%$ presented a significantly higher incidence of Molecular Response and better survival. Therefore, a combination of the molecular response at 3 months with the WBC count at presentation provided accurate predictions of the deep molecular response of imatinib-treated CML-CP patients. The WBC count at presentation might be used to differentiate patients at the beginning of imatinib treatment. [32]

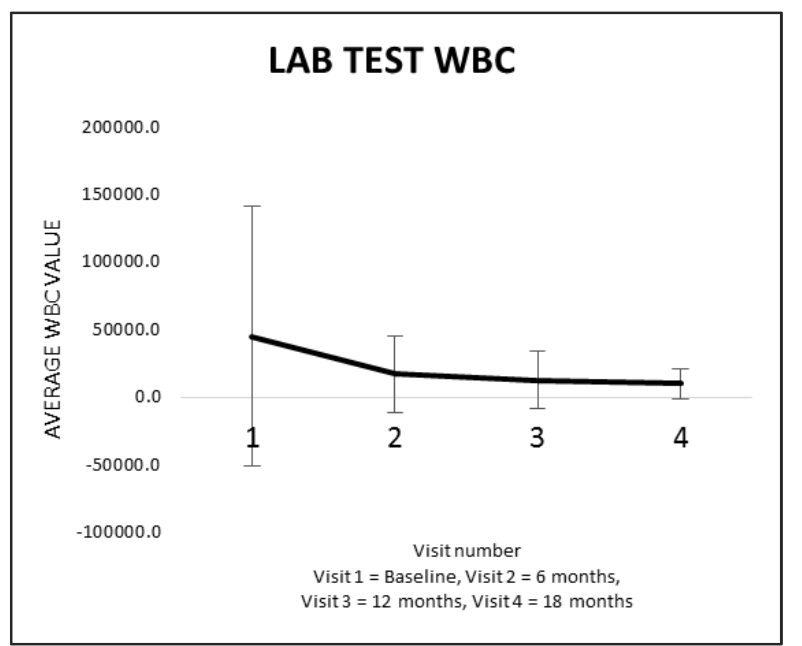

Figure 6. WBC Value Changes in Response to Imatinib (After 6, 12 \& 18 months).

In current study, similar type of results were observed that WBC count decreases from baseline to 8 months of treatment period. Mean WBC value was found $45170.4 \pm 96300.94 / \mathrm{cmm}$ at Day $0,17236.1 \pm 28477.32 / \mathrm{cmm}$ at $6^{\text {th }}$ month, $12637.8 \pm 21387.45 / \mathrm{cmm}$ at $12^{\text {th }}$ month and $9997.2 \pm 10830.94$ $/ \mathrm{cmm}$ at $18^{\text {th }}$ month visit by patients. Same has been presented in figure.

There was no major difference observed with age groups i.e. $\leq 35$ years, 36 to 50 years and $>50$ years of age.

There was no major difference observed with gender groups i.e. Male and Female.

There was a significant difference observed with old vs. newly diagnosed patients.

Depending on the observations, it can be concluded that WBC count at presentation might be used to differentiate patients at the beginning of imatinib treatment. [31]

\section{PLATELETS}

In the current study, mean Platelets count was found $274770.4 \pm 241751.63 / \mathrm{cmm}$ at Day 0, 288515.3 $\pm 197887.52 / \mathrm{cmm}$ at $6^{\text {th }}$ month, $319924.5 \pm 186724.88 / \mathrm{cmm}$ at $12^{\text {th }}$ month and $321591.8 \pm 102412.02 / \mathrm{cmm}$ at $18^{\text {th }}$ month. 


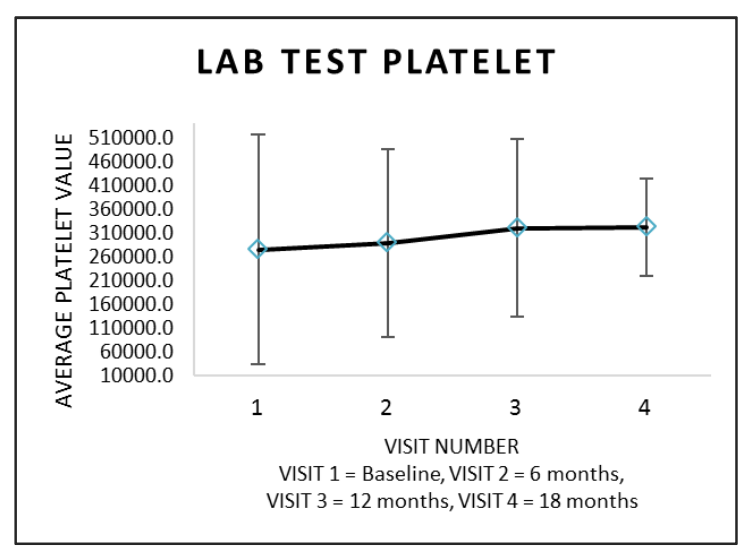

Figure 7. Platelets Value Changes in Response to Imatinib (After 6, 12 \& 18 months).

As per case study by A. S. Vomhagen et al., platelet dysfunction and bleeding disorder in $B C R-A B L^{+}$chronic myeloid leukemia can successfully be treated with imatinib. Author also suggested to monitor platelet function in future studies using imatinib to treat patients with chronic myeloid leukemia. [33] However, O. M. Akay et al. demonstrated that a significant proportion of CML patients (85\%) have different patterns of platelet dysfunction and imatinib therapy has neither a positive nor a negative impact on these functional defects. [34] Similarly, as per U.S. Mogalluru et al., no significant difference is noted in parameters measured using ristocetin and collagen as agonists when compared among pre and post imatinib phases and controls. The normalization of aggregation parameters may be attributed to either partial or complete suppression of clonal abnormal megakaryocytopoiesis and restoration of normal megakaryocytopoiesis by imatinib mesylate therapy in BCR-ABL positive CML. [32] As per study by A. Quinta's-Cardama et al., dasatinib and to some extent, imatinib produce abnormalities in platelet aggregometry testing. [35]

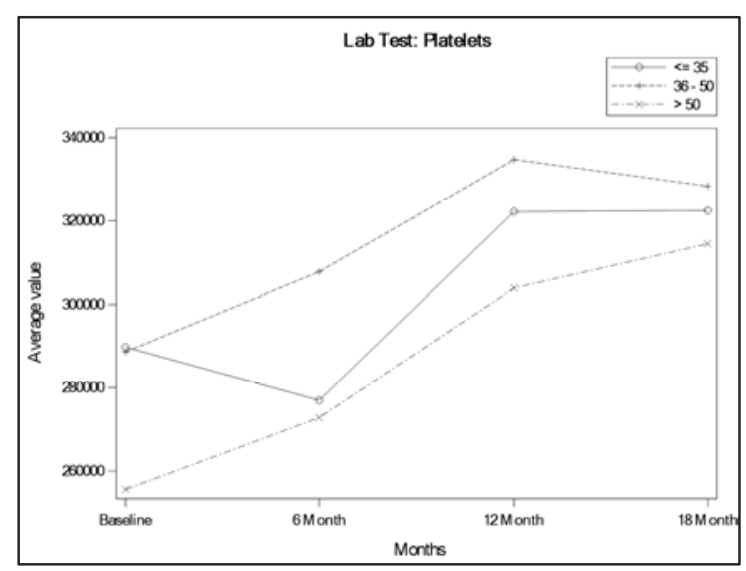

Figure 8. Platelets Value Changes in Response to Imatinib (After 6, 12 \& 18 months).

Moreover, in the current study, it was observed that in age group $\leq 35$ years, after start of treatment, patient platelets count were decreased but after 6 months it was started increasing. However, in age group 35 to 50 years and $>50$ years, platelet count was increasing. Same has been presented in figure.
When platelets counts compared as per gender, it was observed that in male patients it was slowly increasing however in male patients it was observed that it was slowly increased and later it was decreasing after 12 months of treatment. Same has been presented in figure.

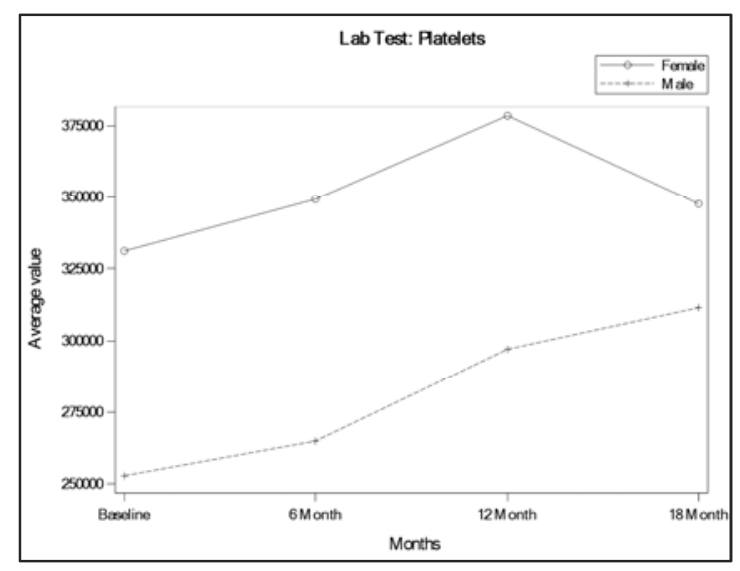

Figure 9. Platelets Value Changes in Response to Imatinib (After 6, 12 \& 18 months).

In continuation to above observation, it was observed that in old diagnosed patients, the patient's platelet count was in increasing pattern however in patients who are diagnosed newly in that there was decrease in platelet count in first 6 months, then increase in platelet count from $6^{\text {th }}$ to $12^{\text {th }}$ month and later it was again decreasing pattern from $12^{\text {th }}$ to $18^{\text {th }}$ month of treatment.

In conclusion, there might not be any trend for platelets however after extrapolating the study, we can have correlation for the effect of imatinib according to age, gender and duration of CML diagnosis.

\section{BASOPHILS}

In current study, mean basophils count was found $2.5 \pm 3.53 \%$ at Day $0,2.5 \pm 11.64 \%$ at $6^{\text {th }}$ month and $1.7 \pm 2.65 \%$ at $12^{\text {th }}$ month visit by patients.

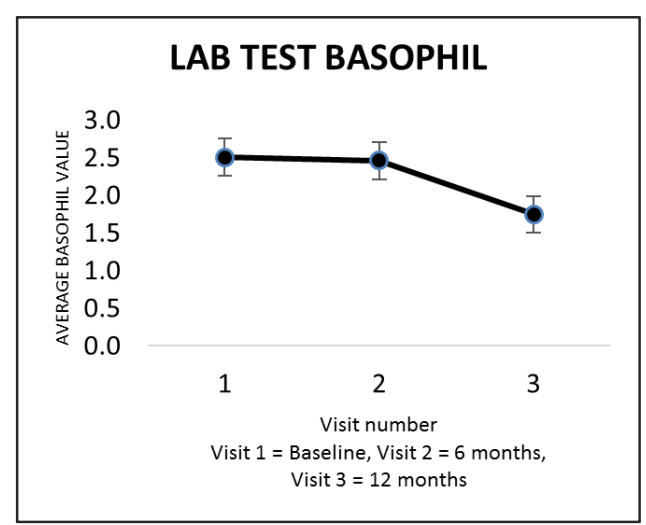

Figure 10. Basophil Value Changes in Response to Imatinib (After 6, 12 \& 18 months).

According to study by A. M. El-Ghammaz, Histamine is a specific product of basophils and is highly upregulated in CML. Histidine decarboxylase (HDC) is the key enzyme involved in histamine generation. This enzyme is expressed in 
basophil-committed progenitors and in mature basophils. Interleukin-3, a major differentiation factor for basophils, has been reported to induce the expression of HDC and thus the synthesis of histamine in myeloid progenitors. In CML cells, BCR-ABL induces the expression of HDC and, in turn, the synthesis of histamine. In line with this observation, imatinib was found to counteract BCR-ABL-induced expression of HDC and synthesis of histamine. Also, rare patients with high basophil counts $(>20 \%)$ have developed urticarial eruptions after taking imatinib, presumably because of the histamine release from basophils. [38]

Moreover, in the current study, it was observed that, in age group $\leq 35$ years, basophils count increases intitally and then start to decrease however in other age groups it was continuously decreasing.

In both male as well as female, it was observed that basophil count was in decreasing pattern only.

However, in old patient diagnosed long back for CML and taking imatinib treatment, basophil count was found lower from initial start of study till end of study however in newly identified patients, it was observed that basophil count was higher and decreases with duration of treatment.

\section{EOSINOPHIL}

In current study, it was observed that mean eosinophil count was found $3.8 \pm 2.89 \%$ at Day $0,3.1 \pm 2.69 \%$ at $6^{\text {th }}$ month and $2.2 \pm 2.14 \%$ at $12^{\text {th }}$ month in CML patients. On Day 0, maximum Eosinophil counts observed was $15.0 \%$, however after 6 months of Imatinib treatment for CML, eosinophil count decreased to maximum $14.0 \%$ whereas after 12 months it was observed as maximum $12.0 \%$.

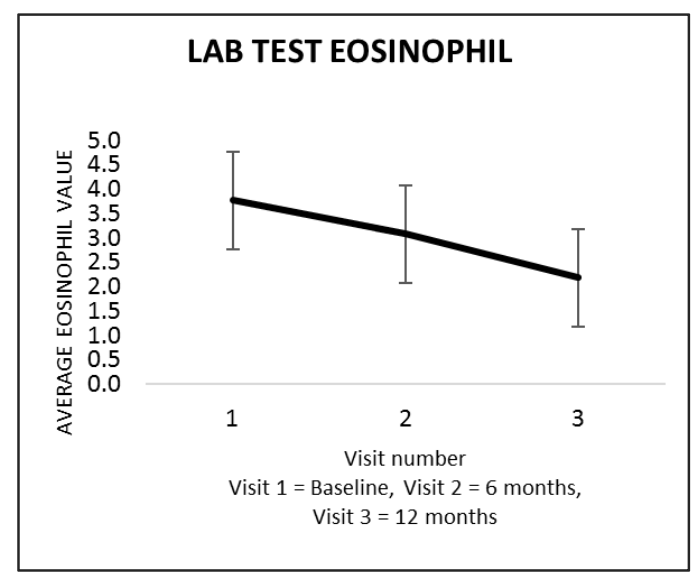

Figure 11. Eosinophil Value Changes in Response to Imatinib (After 6, 12 \& 18 months).

A. Pardanani et al. studied that, previously reported the efficacy of imatinib mesylate for the treatment of 5 patients with HES. Here, It was described that treatment responses of 5 additional patients with HES, and 2 patients with eos-CMD. This study confirms prior observations of the efficacy of imatinib for treatment of HES and potentially further extends the indications for use of this agent for therapy of select cases of eos-CMD. [42]

There was no major difference observed with age groups i.e. $\leq 35$ years, 36 to 50 years and $>50$ years of age.
There was no major difference observed with gender groups i.e. Male and Female.

There was no major difference observed with groups newly identified CML patients vs. old identified CML patients.

\section{LYMPHOCYTES}

In current study, mean lymphocytes count was found $29.4 \pm 15.08 \%$ at Day $0,28.3 \pm 12.81 \%$ at $6^{\text {th }}$ month and $26.1 \pm 14.59 \%$ at $12^{\text {th }}$ month.

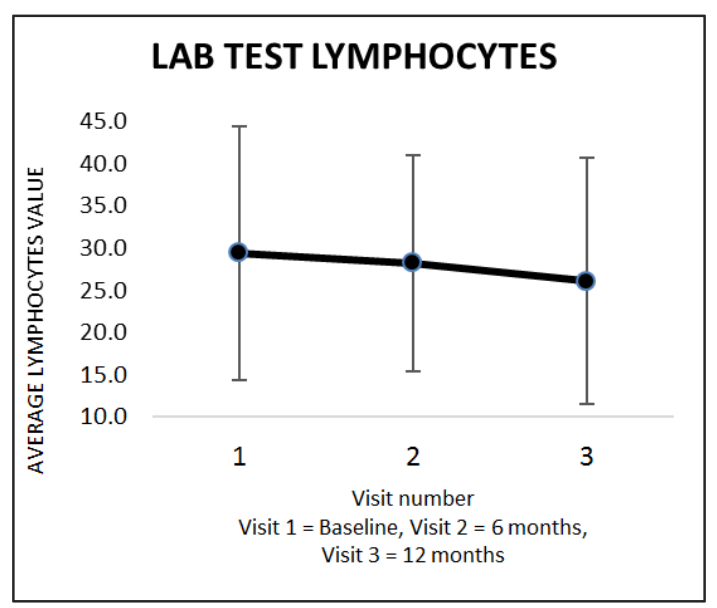

Figure 12. Lymphocytes Value Changes in Response to Imatinib (After 6, 12 \& 18 months).

As mentioned by $\mathrm{K}$ Cwynarski et al., imatinib inhibits T-lymphocyte proliferation induced by allogeneic Peripheral blood mononuclear cells (PBMC) in dose dependent manner. [44]

TKIs had a significant and differential off-target effect on the numbers and proportions of immune effector cells. As mentioned by P. Rohon et al., there is no any significant effect of imatinib on lymphocytes. [46]

It has been observed that, in age group $\leq 35$ years of age, initially lymphocytes count increases and later on it starts decreasing where as in age group 36 to 50 years and $>50$ years, the lymphocytes counts decreases i.e. immune system decreases for all age group more than 36 years. Same has been presented in figure.

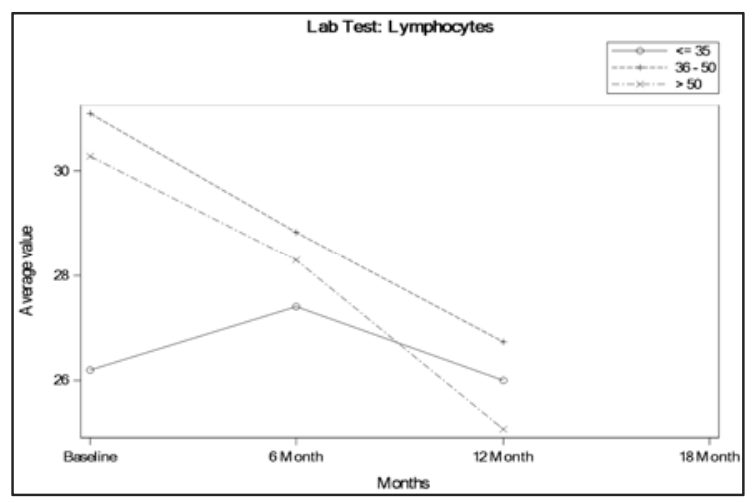

Figure 13. Lymphocytes Value Changes in Response to Imatinib (After 6, 12 \& 18 months).

There was no major difference observed with gender groups i.e. Male and Female. 
In newly diagnosed patients, it has been observed that due to imatinib treatment, lymphocytes count increases i.e. immune system increases whereas in patients diagnosed from long time who are already on imatinib treatment, in such patient's immune system (lymphocytes count) decreases. Same has been presented in figure.

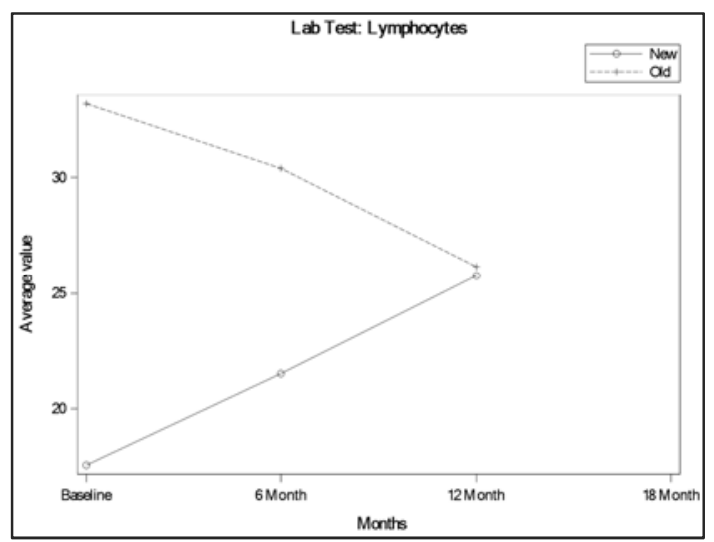

Figure 14. Lymphocytes Value Changes in Response to Imatinib (After 6, 12 \& 18 months).

\section{METAMYELOCYTES}

In current study also, the mean metamyelocytes value was found $6.7 \pm 3.85 \%$ at Day $0,3.6 \pm 3.16 \%$ at $6^{\text {th }}$ month, $3.3 \pm 3.73 \%$ at $12^{\text {th }}$ month and $2.6 \pm 2.61 \%$ at $18^{\text {th }}$ month. It was observed continuous decrease of metamyelocytes counts with imatinib treatment.



Figure 15. Meta Myelocytes Value Changes in Response to Imatinib (After 6, $12 \& 18$ months).

As per L. O. Ngolet et al., in a case study, patient having 9\% total metamyelocytes however after 11 months of treatment and 4 month of discontinuation of imatinib, patient was found with $6 \%$ of metamyelocytes. It can be considered that imatinib has effect on metamelocytes count which lead to decrease after treatment. [47]

Moreover to above studies mentioned, the study done by Khandelwal A et al., metamyelocytes count on day 1 was $45 \%$ however after imatinib treatment on day $7=11 \%$, on day $10=$ $3 \%$, on day $15=$ not detectable however after stopping imatinib on day $37=6 \%$ of metamyelocytes were found. It seems to conclude that there is direct or indirect impact of imatinib on metamyelocytes count. [49]

There was no major difference observed with age groups.

There was minor difference observed with gender groups i.e. Male and Female.

There was minor difference observed with new vs. old diagnosed CML patient groups.

\section{MYELOCYTES}

In current study, it was observed that after imatinib treatment start, myelocytes count decreased till 12 months and later it was observed that myelocytes count start increasing. It can be considered that initial decrease in myelocytes were due to response to treatment however due to drug resistance/not response to treatment, myelocytes count starts increasing. The lab report found were: Mean myelocytes value $6.4 \pm 4.53 \%$ at Day $0,3.1 \pm 2.53 \%$ at $6^{\text {th }}$ month, $3.0 \pm 2.83 \%$ at $12^{\text {th }}$ month and $3.3 \pm 2.63 \%$ at $18^{\text {th }}$ month.

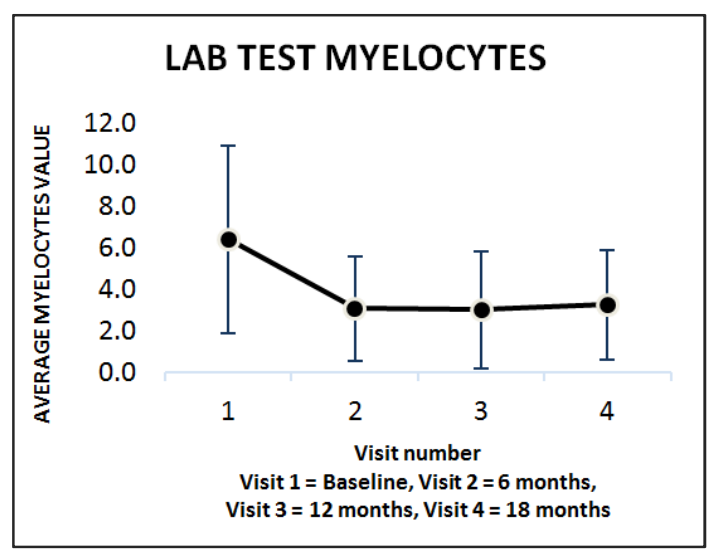

Figure 16. Myelocytes Value Changes in Response to Imatinib (After 6, 12 \& 18 months).

As per case study done by L. O. Ngolet et al., initially myelocytes were $4 \%$ in the peripheral blood. Cytogenetic response was studied in bone marrow aspiration 6 months after imatinib initiation and found that myelocytes count increased to $9 \%$. [47]

Difference was observed with age groups in CML patient. Graphical comparison for the same has been presented as per figure.

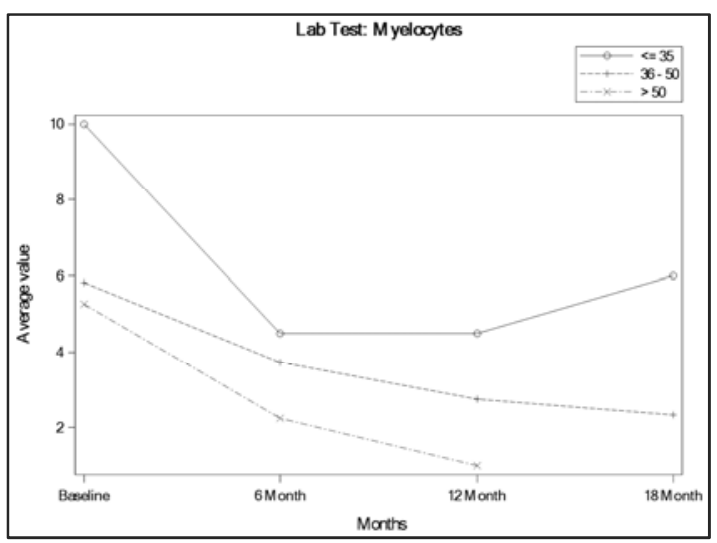

Figure 17. Myelocytes Value Changes in Response to Imatinib (After 6, 12 \& 18 months). 
It has been found that in age group $\leq 35$, myelocytes count was higher and it decreases with treatment however after 6 month it starts increasing and drastic rise in myelocytes occurs after 12 months of treatment period.

There was a significant difference found in gender male/female for myelocytes. In female it is observed that myelocytes decreases with duration of treatment however in male it decreases till 6 months and again start increasing after 6 month of treatment. Same has been presented in figure.

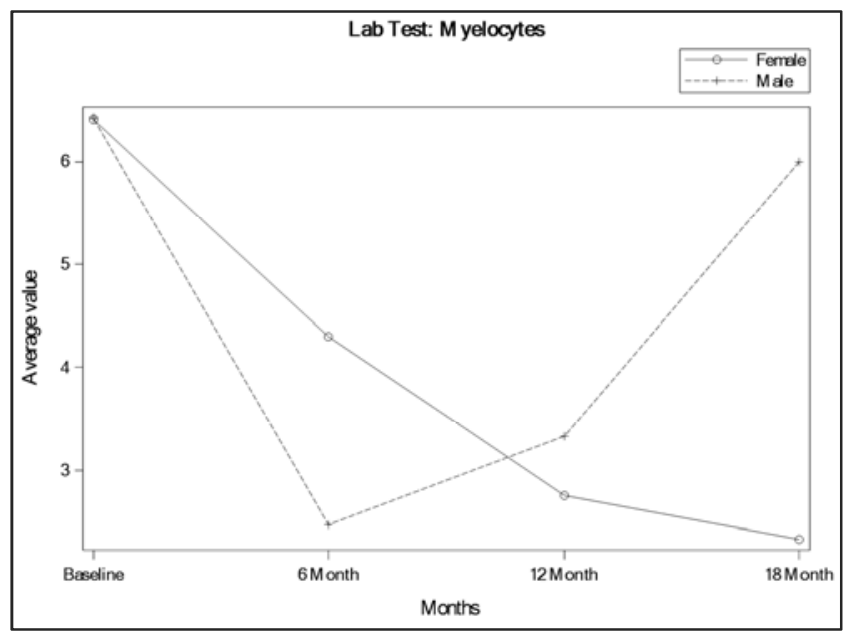

Figure 18. Myelocytes Value Changes in Response to Imatinib (After 6, 12 \& 18 months).

In newly diagnosed patients with CML, it has been observed that myelocytes count was continuously decreasing however in old CML patients, there was no any pattern observed. In old CML patients, it was found increase/decrease with duration of treatment. Same has been presented in figure.

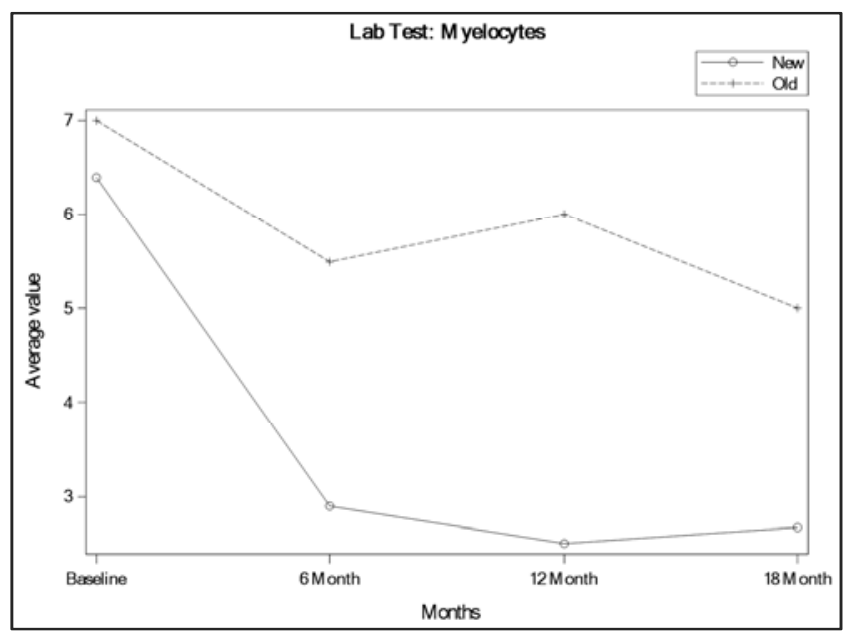

Figure 19. Myelocytes Value Changes in Response to Imatinib (After 6, 12 \& 18 months).

\section{NEUTROPHILS}

In current study, mean neutrophils count was found $54.8 \pm 13.63 \%$ at Day $0,53.0 \pm 11.51 \%$ at $6^{\text {th }}$ month and $45.8 \pm 12.59 \%$ at $12^{\text {th }}$ month.

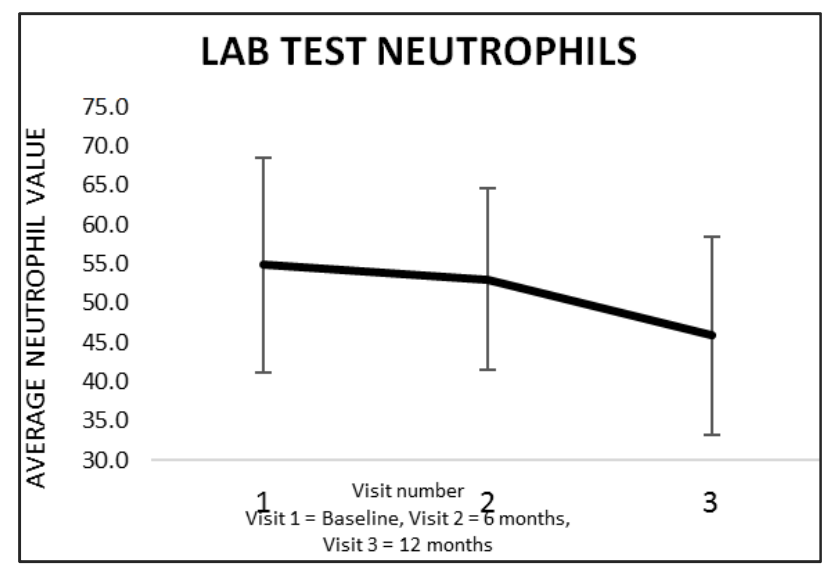

Figure 20. Neutrophils Value Changes in Response to Imatinib (After 6, 12 \& 18 months).

As per Yu-Yan Hwang et al., persistent neutropenia was observed after imatinib treatment. [66] SAWYERS et al. patients treated with $400 \mathrm{mg}$ and $600 \mathrm{mg}$ of imatinib, most common grade 4 abnormalities was neutropenia. [50] As per N. Singhal et al., neutropenia is the most common side effect of imatinib treatment. For neutrophils less than $500 / \mathrm{mm}^{3}$, it is recommended to do bone marrow examination. If the marrow is hypercellular or blasts are greater than $30 \%$, then imatinib is continued. [51]

There was no major difference observed with age groups.

There was no major difference observed with gender differences i.e. between male and female patients.

As per graphical presentation below, in newly diagnosed patients, neutrophils count increases initially and then after starts decreasing however in previously diagnosed patients, neutrophils count decreases continuously. Same has been presented in figure.

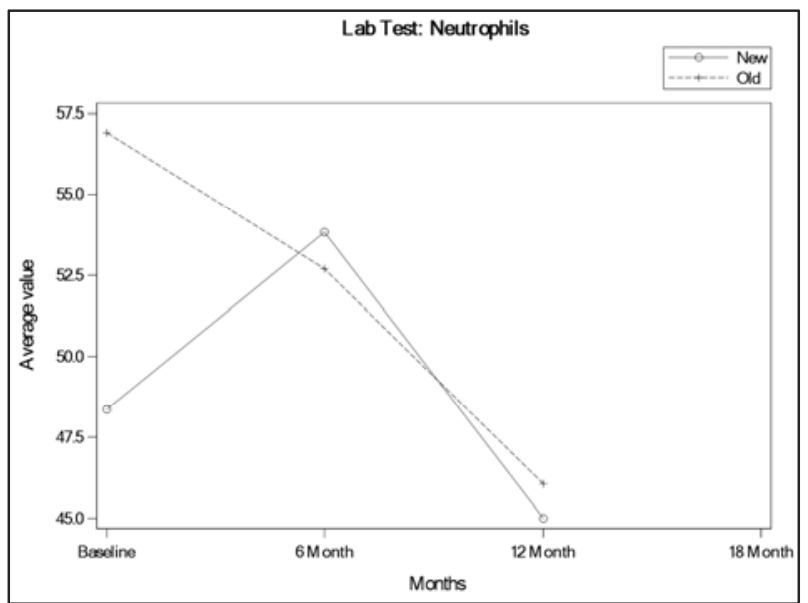

Figure 21. Neutrophils Value Changes in Response to Imatinib (After 6, 12 \& 18 months).

\section{NORMOBLAST}

The change in value of normoblast from baseline to $18^{\text {th }}$ Months were: Mean normoblast count was found $1.3 \pm 0.58 / 100 \mathrm{WBC}$ at Day $0,1.8 \pm 0.50 / 100 \mathrm{WBC}$ at $6^{\text {th }}$ month, $1.0 \pm 0 / 100 \mathrm{WBC}$ at $12^{\text {th }}$ month and $2.0 \pm 0 / 100 \mathrm{WBC}$ at $18^{\text {th }}$ month. 


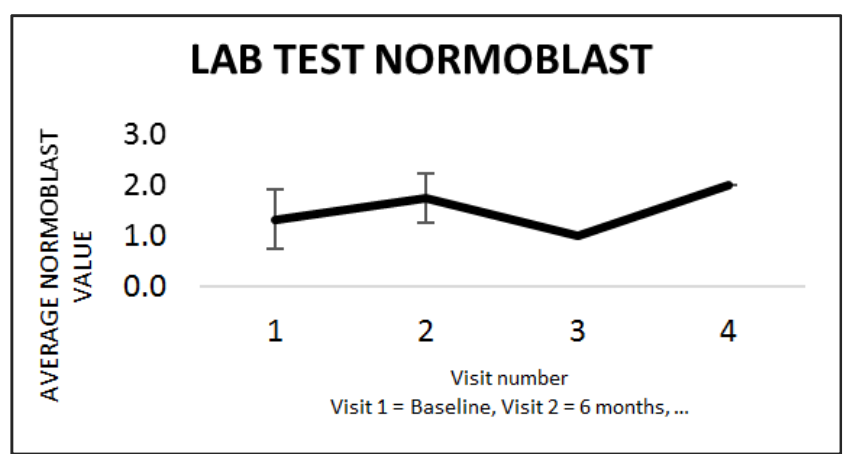

Figure 22. Normoblast Value Changes in Response to Imatinib (After 6, 12 \& 18 months).

There was no any significant relation or change in normoblast count after treatment with imatinib observed. No particular relation with different age group, change in gender and newly or already diagnosed patients were observed.

PROMYELOCYTES

In current study, mean promyelocytes value was found $4.7 \pm 2.09 \%$ at Day $0,2.8 \pm 2.62 \%$ at $6^{\text {th }}$ month, $2.4 \pm 2.95 \%$ at $12^{\text {th }}$ month and $2.3 \pm 1.89 \%$ at $18^{\text {th }}$ month which shows decrease in promyelocytes count with duration of treatment.

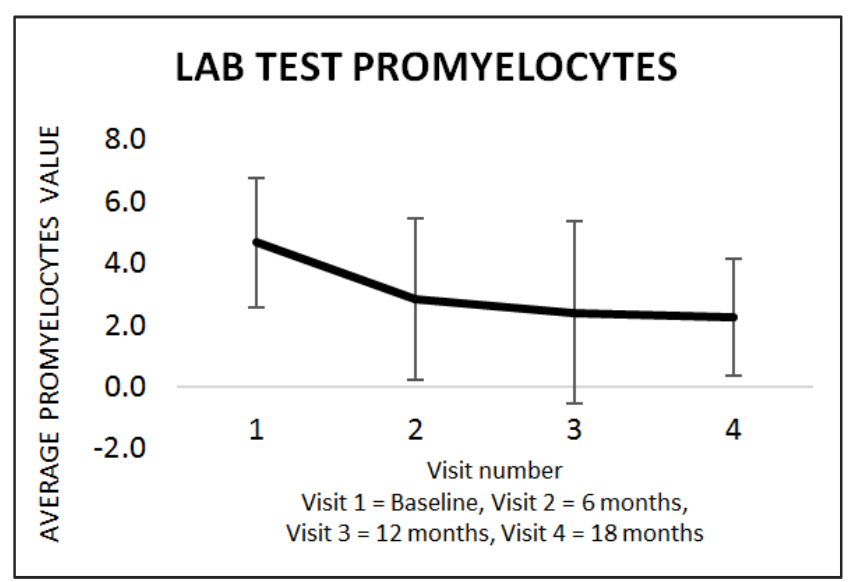

Figure 23. Promyelocytes Value Changes in Response to Imatinib (After 6, 12 \& 18 months).

In age group $\leq 35$ years, promyelocytes count initially increases and after 6 month of treatment it starts decreasing however in age groups $>35$ years, promyelocytes count decreases with duration of treatment. It has been presented in figure.

There was no any significant difference found in patients male and female patients. Moreover, there was no any significant pattern observed in patient already diagnosed with CML (old patients in study) whereas there was decrease in promyelocytes count in newly diagnosed patients with CML.

BLASTS

In this study, mean blast cells count was found $8.3 \pm 13.67 \%$ at Day $0,3.3 \pm 3.87 \%$ at $6^{\text {th }}$ month, $2.3 \pm 4.09 \%$ at $12^{\text {th }}$ month and $2.7 \pm 3.61 \%$ at $18^{\text {th }}$ month.

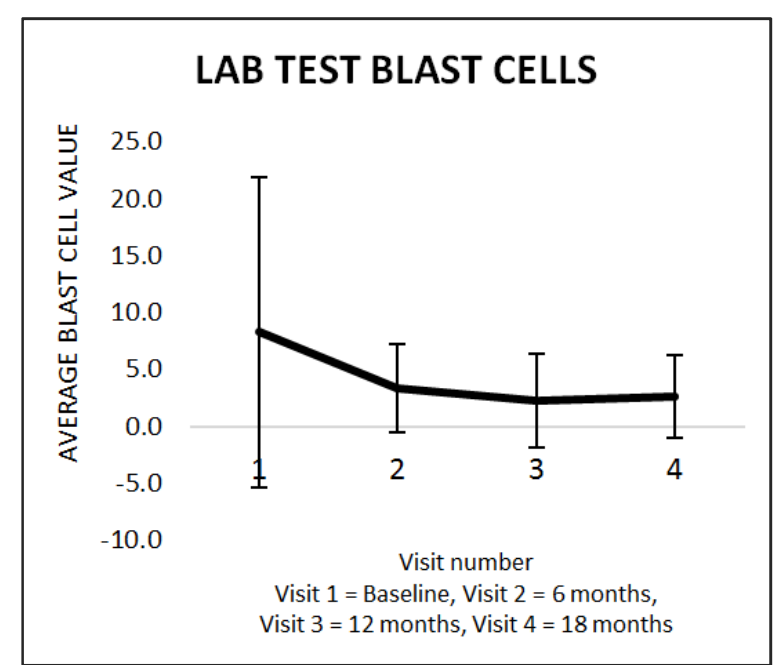

Figure 24. Blast Cells Value Changes in Response to Imatinib (After 6, 12 \& 18 months).

As per Yin $\mathrm{Xu}$ et al, the time from imatinib therapy commencement to blast crisis was 7 to 10 months among the patients in study. [52]

As mention on Texas Oncology (BLASTIC MYELOID LEUKEMIA,

https://www.texasoncology.com/types-of-cancer/leukemia/ch ronic-myeloid-leukemia/blastic-phase dated 04 Oct 2018), Patients were treated with Gleevec in daily oral doses of 400 $\mathrm{mg}$ or $600 \mathrm{mg}$. Eight percent of patients experienced a complete hematologic response, seven percent experienced a complete cytogenetic response, and half the patients survived for longer than seven months. Drug-related adverse events led to discontinuation of therapy in $5 \%$ of patients, most often because of low blood cell counts, skin disorders, or gastrointestinal reactions. The researchers concluded that these results demonstrate that Gleevec has substantial activity and a favorable safety profile when used as a single agent in patients with CML in BC. [53]

In age group between 36 to 50 years, initially blasts count found higher compared to $<36$ years of age group and $>50$ years of age group.

In female patients, blast cells found higher than in male. Moreover, blast crisis is also observed in female patient after 2 months of treatment where as in male patients blast crisis till 18 months is not observed.

In newly diagnosed patients, pattern was found that blasts cells are higher during diagnosis and it decreases with duration of treatment whereas in old diagnosed patients, blasts cells count found near to normal level due to already ongoing treatment however blast crisis may be observed during the study.

\section{BAND FORM CELLS}

In current study, it was found that band form cells were higher during initial diagnosis however after start of Imatinib treatment band form cells decreases with duration of treatment. 


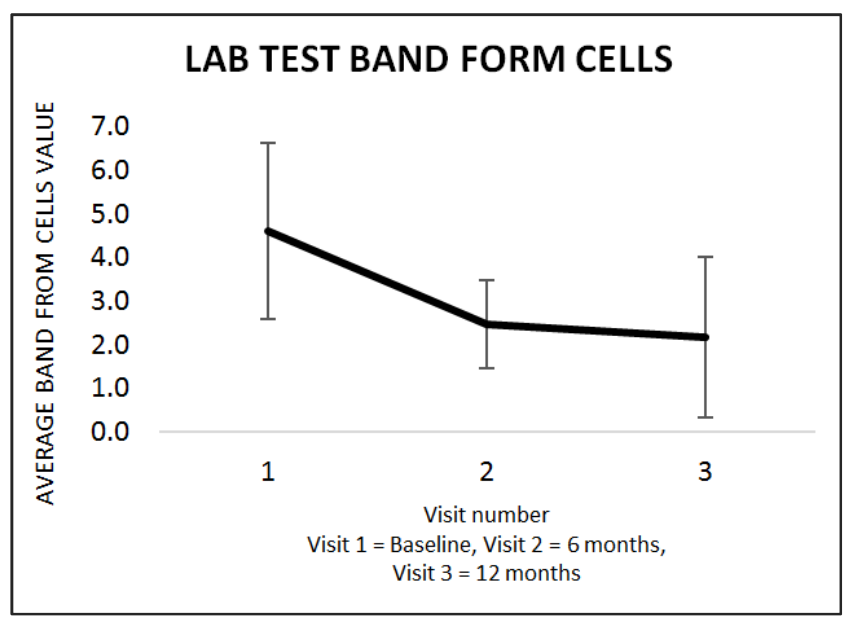

Figure 25. Band Form Cells Value Changes in Response to Imatinib (After 6, $12 \& 18$ months).

According to the 2008 World Health Organization (WHO) diagnostic criteria for CNLThe leukocytosis is $>25<109 / \mathrm{L}$; $80 \%$ of leukocytes are segmented neutrophils/band forms; and $10 \%$ are immature granulocytes. [55]

As per study by Pessach I et al., band form cells were found higher (3\%) than the normal range. 55 Similarly in study by, G. A. Hamid et al., band forms found were $2 \% .158$ Whereas as per S. Duarte et al., band forms found were $11 \%$. [56]

In age group $\leq 35$ years age, Band form cells count decreases initially however after 6 months of treatment it start increasing. Whereas in other age groups there was decrease in band form cells after treatment with Imatinib. It has been presented in figure.

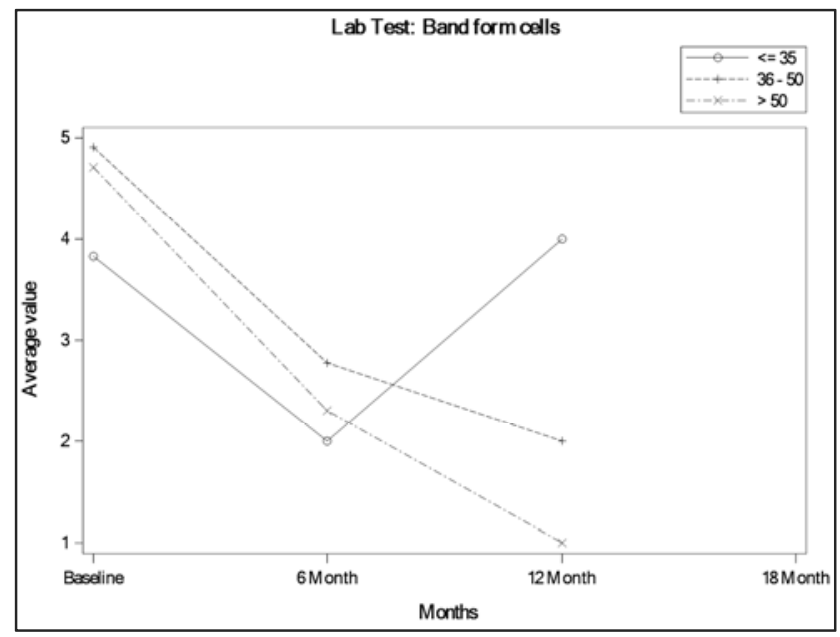

Figure 26. Band Form Cells Value Changes in Response to Imatinib (After 6, $12 \& 18$ months).

There was no any significant difference found between both the genders i.e. male and female.

In patients newly diagnosed with CML, the band form cells counts decreases with duration of treatment however in old diagnosed patients, initially band form cells count decrease and after 6 month of treatment period it starts increasing. Graphical presentation for the same has been found as per figure.

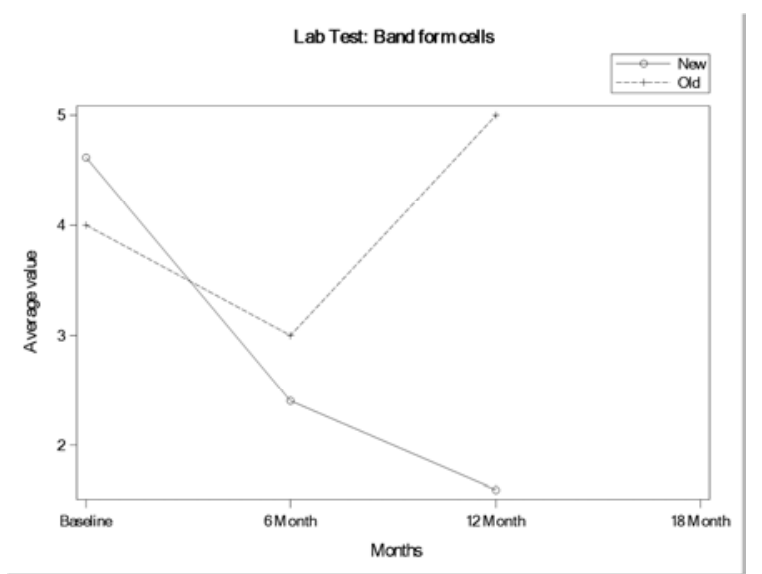

Figure 27. Band Form Cells Value Changes in Response to Imatinib (After 6, $12 \& 18$ months).

\section{SGPT \& CREATININE}

Mean SGPT value was found $23.09 \pm 11.33 \mathrm{U} / \mathrm{L}$ at Day 0 , $27.67 \pm 14.61 \mathrm{U} / \mathrm{L}$ at $6^{\text {th }}$ month, $28.08 \pm 11.96 \mathrm{U} / \mathrm{L}$ at $12^{\text {th }}$ month and $29.23 \pm 6.93 \mathrm{U} / \mathrm{L}$ at $18^{\text {th }}$ month visit of patients.

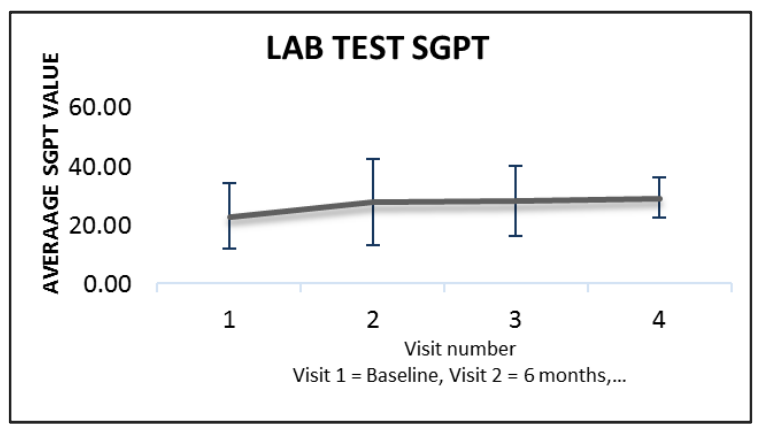

Figure 28. SGPT Value Changes in Response to Imatinib (After 6, 12 \& 18 months).

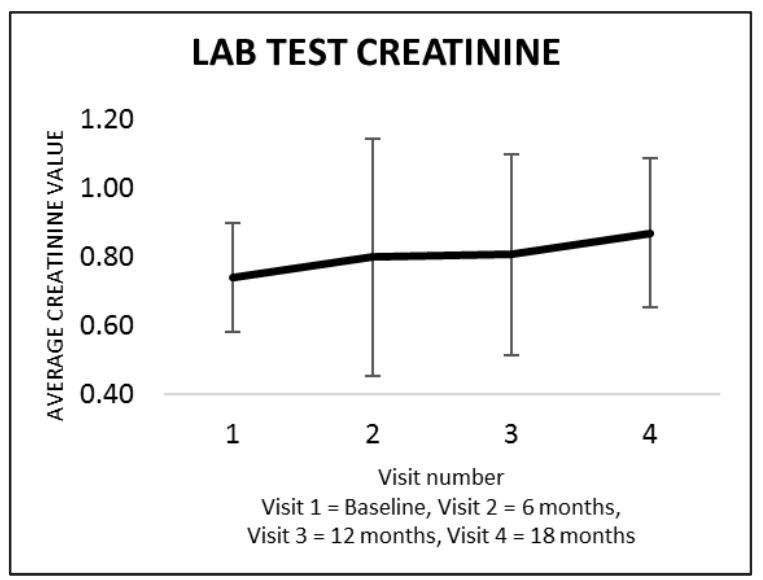

Figure 29. Creatinine Value Changes in Response to Imatinib (After 6, 12 \& 18 months).

Mean creatinine value was found $0.74 \pm 0.16 \mathrm{mg} / \mathrm{dL}$ at Day 0 , $0.80 \pm 0.35 \mathrm{mg} / \mathrm{dL}$ at $6^{\text {th }}$ month, $0.81 \pm 0.29 \mathrm{mg} / \mathrm{dL}$ at $12^{\text {th }}$ month and $0.87 \pm 0.22 \mathrm{mg} / \mathrm{dL}$ at $18^{\text {th }}$ month visit of patients.

As mentioned by H. K. Al-Ali et al., elevated levels of SGOT and SGPT should not automatically be ascribed to hepatotoxicity. Elevated CK levels correlate with MCR, 
possibly reflecting higher drug levels. Longer follow-up is needed to determine if imatinib-induced myotoxicity may cause permanent muscle damage and if patients should be advised to take special precautions, such as the avoidance of strenuous physical activity. 57

There were no significant difference in SGPT and Creatinine depending on age group of the patient.

SGPT level was increases with treatment duration however the SGPT level was high in male compared to female patients. Similar result was observed in creatinine level.

In newly diagnosed patients, after start of treatment with Imatinib, a drastic rise in SGPT level was observed which leads to decrease however in old patients, SGPT increases with duration of treatment. There was no significant difference observed in creatinine level in new or already diagnosed patients.

\section{POLYMERASES CHAIN REACTION}

In current study performed, Mean PCR value (BCR-ABL/ABL ratio) was found $0.245 \pm 1.16$ at Day 0, $0.824 \pm 1.51$ at $6^{\text {th }}$ month, $4.086 \pm 9.58$ at $12^{\text {th }}$ month and $6.713 \pm 11.32$ at $18^{\text {th }}$ month.



Figure 30. PCR Value Changes in Response to Imatinib (After 6, 12 \& 18 months).

As per Ilaria S. et al., BCR-ABL1 molecular monitoring by RQ-PCR is relied upon to ensure that TKI-treated patients are on track to achieve an optimal response, to define the endpoints of clinical trials, and to determine criteria for a safe trial of cessation of TKI therapy after having sustained a deep molecular response. Molecular responses defined by RQ-PCR have been shown to be robust indicators of clinical outcome, yet the biology of BCR-ABL1 molecular response is relatively complex. During the study, it was also mentioned that due to resistance with a kinase domain mutation, PCR count increases i.e. BCR-ABL/ABL ratio increases. [65]

Reverse transcriptase polymerase chain reaction (RT-PCR) chosen as the method of choice to determine the transcript variant of BCR-ABL, is one of the most sensitive methods for this purpose. [65]

As mentioned inn article by E. J. Jabbour et al., PCR keeps changing - rising and falling. If it rises above $1 \%$, then something is wrong. Either the patient is not taking his or her medication, or there is true resistance. [67]

There was no any significant difference due in factor considering age. In all age groups of patients, PCR value increase with duration of treatment.

Similarly, there was no any gender effect on PCR value. PCR value increase with duration of treatment.

Moreover, there was no any effect on PCR value due to whether patient is newly diagnosed or already diagnosed with CML. PCR value increase with duration of treatment.

\section{PRODUCT LIMIT SURVIVAL ESTIMATE}

Among patients presenting in AP, survival has improved significantly by year of therapy. The estimated 8-year survival rate has increased from less than $20 \%$ before 1990 , to $45 \%$ in the years $1991-2000$, to $75 \%$ since 2001 . This suggests the strong impact of imatinib therapy in AP-CML and the need to develop new "AP" criteria that predict for a very short survival. [60]

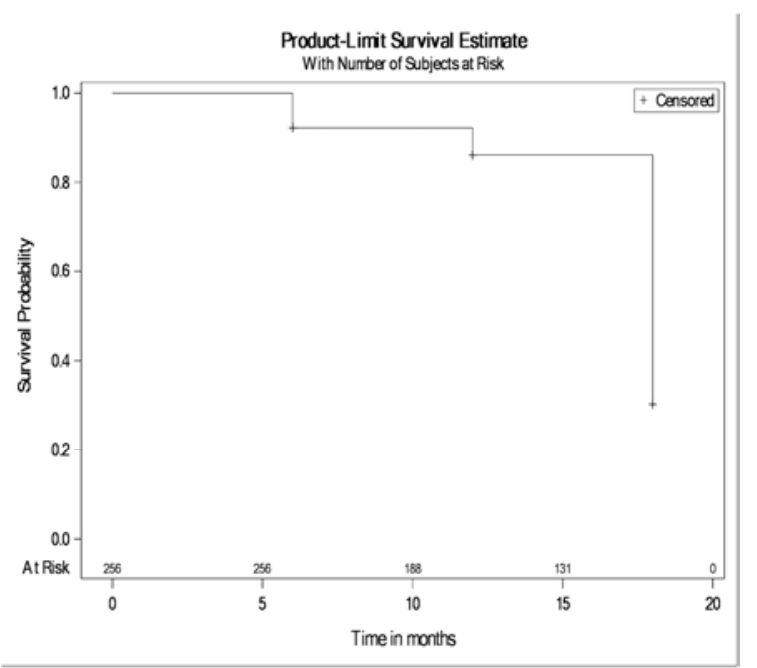

Figure 31. Product Limit Survival Estimate to Imatinib (After 6, 12 \& 18 months).

In current study, it has been observed that the survival rate was decreasing with increase duration of treatment which also confirms either of two reasons as per following:

1. Either patient is not taking medication,

2. Or patient is getting resistance from the treatment

It has been found from many literature from other countries that CML patient get resistance to Imatinib after 12 to 18 months. Similar type of result was found in current study from western region population that patients getting resistance after app. 12 months of treatment due to which survival rate was drastically decreased.

Graphical presentation for the same has been mentioned in figure.

Patients respond suboptimally or fail to respond to imatinib for a variety of reasons, including lack of adherence to prescribed treatment because of toxicity, pharmacokinetic factors, and drug resistance due to molecular/cytogenetic mechanisms. [61]

Imatinib dose escalation may be considered in some patients who experience a loss of response on $400 \mathrm{mg}$ /day 
Imatinib or in those with low Imatinib plasma levels. Treatment should be changed to Dasatinib or Nilotinib if a response is lost in patients who received higher doses of Imatinib (i.e., 600-800 mg/day) or if Imatinib-resistant mutations emerge however data about the outcome of patients with variant translocations after therapy with next generation tyrosine kinase inhibitors are limited. [62]

It has been shown that molecular remission is almost never reached through Imatinib therapy. The most common mechanism of relapse for CML patients treated with Imatinib is the appearance of point mutations in the BCR-ABL oncogene that confer resistance to this drug. Insights into the emerging problem of resistance should promote the rational development of alternative, synergistic, and potentially curative treatment strategies. [63]

As mentioned by Z. Iqbal et al., It should be kept in mind that the impact of mutations on imatinib resistance reported to date is based on a single mutation for each patient. As this is the first report of multiple mutations conferring imatinib resistance in one patient and each mutation confers different levels of resistance, the biological significance of more than one $\mathrm{ABL}$ ATP-binding domain mutations conferring imatinib resistance in same patient with a difference in resistance mechanism is still to be determined. However, we theoretically assume that such multiple mutations will result in more complicated imatinib-resistance patterns, which might be much more difficult to manage clinically than CML patients with the single mutation. As little is known about the underlying genetic and molecular reasons for primary imatinib resistance, we hope that this new discovery will help not only unravel the pharmacogenomic basis of primary resistance to such molecularly targeted therapies but will also help in formulating new methods to manage such complicated cases of resistance. ${ }^{64}$

\section{Conclusion}

The most common mechanism of relapse for CML patients treated with Imatinib is appearance of point mutations in the BCR-ABL oncogene that confer resistance to Imatinib. From the study, it can be concluded that resistance to Imatinib might developed within an average time of 12-18 months in CML patients due to which patient survival rate was drastically reduced.

\section{References}

[1] Hejmadi M, Introduction to Cancer Biology, 1st edn, Ventus Publishing, 2010, pp 6-42.

[2] National cancer institute.www.cancer.gov

[3] Kuby J, Goldsby RA, Kindt TJ, Obourne BA, Immunology, 4th edn, W. H Freeman and Company, 2000, pp 501-502.

[4] Knowles MA, Selby PJ, Introduction to Cellular and Molecular Biology of Cancer, 4th edn, Oxford University Press, 2005, pp 15-289.

[5] www.cancerguide.org
[6] NPTEL - Chemistry - Bio-Organic Chemistry of Natural Enediyne Anticancer Antibiotics, Joint initiative of IITs and IISc - Funded by MHRD, Page 1-64.

[7] N. L. Harris et al., A Revised European-American Classification of Lymphoid Neoplasms: A Proposal From the International Lymphoma Study Group, Blood, Sep 1994; 84 (5); pp 1361-1392.

[8] Druker BJ, Talpaz M, Resta DJ, et al. "Efficacy and safety of a specific inhibitor of the BCR-ABL tyrosine kinase in chronic myeloid leukemia.” N. Engl. J. Med. 2001, 344, 31-37.

[9] Kantarjian H, Sawyers C, Hochhaus A, et al, "Hematologic and cytogenetic responses to imatinib mesylate in chronic myelogenous leukemia.” N. Engl. J. Med. 2002, 346, 645-652.

[10] www.nationalcmlsociety.org

[11] www.rxlist.com

[12] www.accessdata.fda.gov

[13] Gschwind H, Pfaar U, Waldmeier F, Zollinger M, Sayer C, Zbinden $\mathrm{P}$, et al, " Metabolism and disposition of imatinib mesylate in healthy volunteers." DMD. 2005, 33, 1503-1512.

[14] Anderson PO, Knoben JE, Troutman WG, Handbook of Clinical Drug Data, 10th edn, McGraw Hill Medical Publishing Division, 2002, pp 266-267.

[15] Tejani S, Sanoski CA, Davis's Pocket Clinical Drug Reference, 1st edn, F A Davis Company, 2009, pp 141-142.

[16] Deininger M, Buchdunger E, Druker BJ, "The development of imatinib as a therapeutic agent for chronic myeloid leukemia." Blood. 2005, 105 (7), 2640-2653.

[17] K. Patton and D. C. Borsoff, "Adverse Drug Reactions", Anaesthesia, 2018, 73 (1), 76-84.

[18] Alan H Turner, Marilyn J Pike and Maureen A Francis, "Haematology what does your blood test mean?, RMIT university", Edited by: Indu Singh 2008, School of Medical Science 2008, 1-12.

[19] Trevor J. Whitbread, "Clinical Biochemistry", Abbey Veterinary Services, MSD and the MSD Veterinary Manual, dated 15 Aug 2017.

[20] Bartlett, J. M. S., \& Stirling D, "A short history of the polymerase chain reaction. Methods in Molecular Biology", Methods Mol Biol. 2003; 226; 3-6.

[21] Kleppe K, Ohtsuka E, Kleppe R, Molineux I, Khorana HG, "Studies on polynucleotides. XCVI. Repair replications of short synthetic DNA's as catalyzed by DNA polymerases", J Mol Biol. 1971; 56 (2); 341-61.

[22] Saiki R. K.; Scharf S., Faloona F., Mullis K. B., Horn G. T., Erlich H. A., Arnheim N., "Enzymatic amplification of betaglobin genomic sequences and restriction site analysis for diagnosis of sickle cell anemia", Science. 1985; 230 (4732); $1350-4$

[23] Erlich, H. A., "PCR technology: principles and applications for DNA amplifications", Stockton Press 1989, NY. Website: https://catalogue.nla.gov.au/Record/183698.

[24] Gibbs, R. A; DNA Amplification by the Polymerase Chain Reaction. Analytical Chemistry, 1990, 62: 1202-1214. 
[25] http://www.pcrstation.com/discovery

[26] Arnheim, N; Erlich, H; Polymerase Chain Reaction Strategy. ANNUAL REVIEW OF BIOCHEMISTRY, 1992; VOL. 61. XIV1992: 131-156.

[27] Erlich, H. A; Gelfand, D; Sninsky, J. J. Recent Advances in the Polymerase Chain Reaction. Science, 1991; 252, 5013, 1643-1651.

[28] Moshfeghi K. et al., Hematologic, liver enzymes and electrolytes changes in chronic myeloid leukemia after Imatinib medication; Indian Journal of Cancer, July-September 2015; 52 (3): 305-307.

[29] R. A. Larson, Chronic Myeloid Leukemia; Chronic myeloid leukemia - Cancer Therapy Advisor, 2018; https://www.cancertherapyadvisor.com/hematology/chronic-m yeloid-leukemia/article/597339/.

[30] D. Prihatni et al., Tyrosine Kinase level and White Blood Cells Count in Untreated and Treated Chronic Myelogenous Leukemia Patients with BCR ABL gene; International Journal of Science and Research, July 2016; 5 (7): 1312-1316.

[31] Y. Qin et al., Combination of White Blood Cell Count at Presentation With Molecular Response at 3 Months Better Predicts Deep Molecular Responses to Imatinib in Newly Diagnosed Chronic-Phase Chronic Myeloid Leukemia Patients; Medicine, January 2016; 95 (2): 1-9.

[32] U. S. Mogalluru et al., Effect of Imatinib Mesylate on Platelet Aggregation Plat Abnormalities in BCR-ABL + CML Patients; Blood Journal, 2008; 112: 1-4.

[33] A. S. Vornhagen et al., Improvement of platelet dysfunction in chronic myelogenous leukemia following treatment with imatinib: a case report; Journal of Medical Case Reports, 2011; 5: $1-4$.

[34] O. M. Akay et al., Platelet Dysfunction in Patients with Chronic Myeloid Leukemia: Does Imatinib Mesylate Improve It?; Turk J Hematol 2016; 33: 127-130.

[35] A. Q. Cardama et al., Tyrosine kinase inhibitor-induced platelet dysfunction in patients with chronic myeloid leukemia; BLOOD, JULY 2009; 114 (2): 261-263.

[36] W. Warit et al., High Prevalence of Platelet Dysfunction Among Patients with Chronic Myeloid Leukemia Receiving Tyrosine Kinase Inhibitors; Blood, 2014; 124: 2781.

[37] M. Radwi et al., Drug-induced immune thrombocytopenia associated with use of tyrosine kinase inhibitor imatinib; Journal of Taibah University Medical Sciences, 2015; 10 (3): 365-368.

[38] A. M. El-Ghammaz et al., Basophil progenitor marker histamine and its relation to the treatment response in Egyptian chronic myeloid leukemia patients; The Egyptian Society of Haematology, 2014; 39 (3): 30-36.

[39] V. F. Furtado et al., Accelerated phase chronic myeloid leukemia: evaluation of clinical criteria as predictors of survival, major cytogenetic response and progression to blast phase; Brazilian Journal of Hematology and Hemotherapy, 2015; 37 (5): 341-347.

[40] M. Anand et al., Chronic myeloid leukemia presenting with absence of basophils and marked dyspoiesis; Indian Journal of Cancer, 2003; 40 (4): 144-147.
[41] $\mathrm{P}$. Valent, The underestimated role of basophils in $\mathrm{Ph}+$ chronic myeloid leukaemia; Eur J Clin Invest., 2018: 1-9.

[42] A. Pardanani, Imatinib therapy for hypereosinophilic syndrome and other eosinophilic disorders; Blood, 2003; 101: 3391-3397.

[43] J. Cortes, Efficacy of imatinib mesylate in the treatment of idiopathic hypereosinophilic syndrome; BLOOD, June 2003; 101 (12): 4714-4716.

[44] K. Cwynarski, Imatinib inhibits the activation and proliferation of normal T lymphocytes in vitro; Leukemia, 2004; 18: 13321339.

[45] L. Legros et al., Imatinib Sensitizes T-cell Lymphocytes From Chronic Myeloid Leukemia Patients to FasL-induced Cell Death: A Brief Communication; Journal of Immunotherapy, FEB 2012; 35 (2): 154-158.

[46] P. Rohon et al., Differential Effects of Imatinib and Dasatinib Ima On Immune Effector Cells in Patients with Chronic Myeloid Leukemia (CML); Blood, 2009; 114: 3285.

[47] L. O. Ngolet et al., Pregnancy and Accelerated Phase of Myeloid Chronic Leukemia Treated with Imatinib: A Case Report from a Developing Country; Case Reports in Hematology, 2016: 1-3.

[48] L. Rice, Every Case of Essential Thrombocythemia Should Be Tested for the Philadelphia Chromosome; American Journal of Hematology, 2005; 78: 71-73.

[49] A. Khandelwal et al., Imatinib resistance in chronic myelogenous leukemia: an emerging challenge; International Journal of Basic \& Clinical Pharmacology, Oct 2014; 3 (5): 908-911.

[50] C. L. Sawyers et al., Imatinib induces hematologic and cytogenetic responses in patients with chronic myelogenous leukemia in myeloid blast crisis: results of a phase II study; BLOOD, MAY 2002; 99 (10): 3530-3539.

[51] N. Singhal, P. P. Bapsy, K. G. Babu, J. George, Chronic Myeloid Leukemia; JAPI, May 2004; 52: 410-416.

[52] Y. Xu, A. E. Wahner, P. L. Nguyen, Progression of Chronic Myeloid Leukemia to Blast Crisis During Treatment With Imatinib Mesylate; Arch Pathol Lab Med, September 2004; 128: 980-985.

[53] Blastic Myeloid Leukemia, Texas Oncology; https://www.texasoncology.com/types-of-cancer/leukemia/chr onic-myeloid-leukemia/blastic-phase, 10/4/2018: 1-6.

[54] R. P. Hasserjian et al., STI571 (Imatinib Mesylate) Reduces Bone Marrow Cellularity and Normalizes Morphologic Features Irrespective of Cytogenetic Response; Am J Clin Pathol 2002; 117: 360-367.

[55] J. Gotlib, J. E. Maxson, T. I. George and J. W. Tyner, The new genetics of chronic neutrophilic leukemia and atypical CML: implications for diagnosis and treatment; BLOOD, Sep 2013; 122 (10): 1707-1711.

[56] S. Duartea, S. C. Pereiraa, E. Rodriguesa, A. Pereira, Concomitant chronic myeloid leukemia and monoclonal B cell lymphocytosis - a very rare condition; Brazilian Journal of Hematology and Hemotherapy, 2017; 39 (2): $167-169$.

[57] J. Hoffman, Increased Serum Creatinine Reversible upon Imatinib Discontinuation, Cancer Therapy Advisor, Mar 2016: 1 . 
[58] E. Vidal-Petiot et al., Imatinib Increases Serum Creatinine by Inhibiting Its Tubular Secretion in a Reversible Fashion in Chronic Myeloid Leukemia; Clinical lymphoma, myeloma \& leukemia, Mar 2016; 16 (3): 169-174.

[59] D. Renard, T. Bouillon, P. Zhou, G. Flesch \& D. Quinn, Pharmacokinetic interactions among imatinib, bosentan and sildenafil, and their clinical implications in severe pulmonary arterial hypertension; British Journal of Clinical Pharmacology, Jan 2015; 80 (1): 75-85.

[60] H. Kantarjian et al., Improved survival in chronic myeloid leukemia since the introduction of imatinib therapy: a single-institution historical experience; Blood, Mar 2012; 119 (9): 1981-1987.

[61] E. J. Jabbour, J. E. Cortes and H. M. Kantarjian, Resistance to Tyrosine Kinase Inhibition Therapy for Chronic Myelogenous Leukemia: A Clinical Perspective and Emerging Treatment Options; Clin Lymphoma Myeloma Leuk., Oct 2013; 13 (5): 515-529.

[62] P. Gadhia, G. Shastri, E. G. Shastri, Imatinib Resistance and Relapse in CML Patients with Complex Chromosomal Variants;
American Journal of Cancer Science, Sep 2015; 4: 43-53.

[63] V. Nardi, M. Azam, G. Q. Daley, Mechanisms and implications of imatinib resistance mtations in BCR-ABL; Current Opinion in Hematology, February 2004; 11 (1): 35-43.

[64] Z. Iqbal, R. T. Siddiqui, J. A. Qureshi \& A. M. Khalid, Case study of primary imatinib resistance and correlation of BCR-ABL multiple mutations in chronic myeloid leukemia; Therapy, 2004; 1 (2): 249-254.

[65] R. Aich et al., Incidence of BCR-ABL transcript variants in patients with chronic myeloid leukemia: Their correlation with presenting features, risk scores and response to treatment with imatinib mesylate; Indian Journal of Medical and Paediatric Oncology, Mar 2014; 35 (1): 26-30.

[66] Yu-Yan Hwang et al., Persistent neutropenia in chronic myelogenous leukemia in chronic phase treated with imatinib mesylate; American Journal of Hematology, Feb 2009: 302-305.

[67] E. J. Jabbour, Use of PCR Testing in Chronic Myeloid Leukemia; Clinical Advances in Hematology \& Oncology, Dec 2015; 13 (12): 808-810. 